\title{
América Latina y conflicto social en el siglo XXI: Escenarios y debates sobre el descuajeringamiento de la relación Estado, mercado y sociedad civil ${ }^{1}$
}

\author{
Latin America and social conflict in the XXI century: Scenarios \\ and discussions on the breakdown of the relationship between \\ the State, market, and civil society
}

JUAN JORGE FAUNDES PEÑAFIEL ${ }^{2}$

Universidad Católica de Temuco, Chile

RECEPCIÓN: 20/O8/20I6・ACEPTACIÓN: 3I/O8/20I6

RESUMEN Se revisan los escenarios sociopolíticos latinoamericanos considerando el mayor o menor avance del proyecto neoliberal y su relación con los movimientos sociales; los debates y consensos sobre la acción colectiva, los movimientos sociales y la llamada «crisis» de los partidos políticos. El trabajo se aborda, primero, desde la matriz, «nacional-social-popular» o «Matriz Socio Política», que distingue entre el rol del Estado, el sistema de representación política que media con la sociedad, institucionalizando las demandas o conflicto sociales, pero que ha sido desarticulada ante el escenario actual de la sociedad "postindustrial globalizada» latinoamericana y se confronta con la propuesta de una matriz «mercado-céntrica» de «Estadomercado-sociedad civil».

I. Este artículo se enmarca en el proyecto Fondecyt «Teorías contemporáneas del reconocimiento. Una lectura crítica de la obra de Honneth, Taylor y Ricoeur», $\mathrm{N}^{\circ}$ I 2070 I-20 I I del que participó el autor como tesista doctoral.

2. Doctor en Procesos Sociales y Políticos en América Latina de la Universidad Arcis. Investigador del Grupo de Investigaciones Jurídicas de la Universidad Católica de Temuco. 
PALABRAS CLAVE Matriz sociopolítica, partidos políticos, movimientos sociales, democracia, América Latina.

ABSTRACT In this paper, we review Latin American sociopolitical scenarios, taking into account the advances of the neoliberal approach and its relationship to social movements. We also highlight the discussions and consensus on collective action, social movements, and the so-called «crisis» of political parties. First, this work addresses the «national-social-popular,» or «sociopolitical,» matrix, which differentiates between the role of the State and the system of political representation used by the public, institutionalizing social demands and conflicts. Then, we examine how this matrix has been dismantled by the current scenario of Latin American's "globalized postindustrial» society and now faces the proposal of a «market-centric» matrix in a «state-market-civil» society.

KeYwords Sociopolitical Matrix, Political Parties, Social Movements, Democracy, Latin America.

"América Latina es hermosa, está llena de arbolitos, paisajes, ríos y agüita» (dijo uno de mis hijos en respuesta a un comentario sobre sus procesos sociales y politicos).

\section{Introducción}

América Latina sufrió profundas transformaciones en las últimas cuatro décadas, tras el ciclo de regímenes autoritarios, principalmente militares y los ajustes estructurales neoliberales, de primera (ochenta) y segunda generación (noveta), transitando a nuevas democracias que muestran esfuerzos y contradicciones en la consolidación de sus institucionalidades.

En este contexto se visualiza un discurso estatal centrado en la búsqueda de mayor justicia social, cruzado por los intereses y el poder de las elites nacionales (nuevas y viejas oligarquías) y los nuevos poderes de la acumulación capitalista global que demanda de manera creciente los recursos naturales de estas sociedades "periféricas», junto a una globalización que fue tejiendo sus redes hasta ser parte del sistema mundo, como compleja red tecnológica, comunicacional, social y de mercados.

Así, en el presente trabajo, nos daremos a la tarea de buscar un modelo o matriz para comprender los escenarios sociopolíticos de América Latina, en 
especial desde dos propuestas teóricas, con especial énfasis en los cambios de la acción colectiva o los movimientos sociales, a fin de visualizar el horizonte de los procesos de democratización en la región y su tensión con la expansión neoliberal global.

Nuestro análisis considera principalmente dos matrices planteadas para analizar las dinámicas sociales y políticas en América Latina. La primera matriz, «nacional-social-popular», que Manuel Antonio Garretón llama «Matriz Socio Política», hace una lectura de los procesos sociopolíticos latinoamericanos, distinguiendo entre el rol del Estado, el sistema de representación política (sistema de partidos políticos) que actúa como mediador en el Estado y la sociedad, institucionalizando las demandas o conflictos sociales ${ }^{3}$. El mismo autor considera que esta matriz ha sufrido un "descuajeringamiento» ${ }^{4}$, una desarticulación, en el marco de la nueva sociedad "postindustrial globalizada» hoy imperante en América Latina que tiene como ejes centrales el consumo, la información y la comunicación ${ }^{5}$. La segunda matriz — propuesta por Juan Carlos Gómez Leyton-, a partir del mismo proceso de transformación de las sociedades latinoamericanas, especialmente los cambios estructurales de las economías (décadas de los ochenta y noventa) y los procesos de democratización post autoritarios, confronta «Estado, mercado y sociedad civil» ${ }^{6}$.

Previamente presentamos un perfil general de los escenarios sociopolíticos latinoamericanos, en particular considerando el mayor o menor avance del proyecto neoliberal global y su relación con los movimientos sociales. En segundo término, abordamos los actores sociales en América Latina, desde una síntesis de los debates y consensos sobre la acción colectiva y los movimientos sociales, hasta un breve acercamiento a los sistemas de representación y los partidos políticos, en particular lo que se ha planteado como su debilitamiento o crisis.

Para estructurar nuestro trabajo -como plantea Revilla- el estudio de la acción colectiva se puede realizar en un nivel «macro», focalizado en la identificación de rasgos comunes, que permiten modelar los procesos de la región, que en este caso se aborda con la revisión de los escenarios sociopolíticos que caracterizaremos bajo cuatro tipos ideales para Latinoamérica. Luego, en el

3. GARretón (200I) p. I 5 .

4. Garretón (2OIO) p. 2 I 5.

5. Garretón (200I) p. 20.

6. GómEZ (2012) p. I70-I72. 
nivel «meso», encontramos «las expresiones concretas de acción y «los significados políticos específicos» que podríamos situar en unas u otras sociedades concretas de la región. En tercer lugar, están los estudios en el nivel «micro» de la situación y demandas de las diferentes expresiones de la acción colectiva, entrando en su respectivo y propio contexto social y político ${ }^{7}$.

Bajo la metodología descrita, realizamos un abordaje en el nivel «macro», mientras, vamos reseñando algunos procesos del nivel «meso» y casos específicos en nivel «micro» a modo ejemplar, con el propósito de alcanzar conclusiones que aporten al debate crítico regional en torno a los impactos de la neoliberalización en los procesos de la acción colectiva de América Latina. Conforme ello, sostendremos que el avance neoliberal en estas sociedades y sus economías, ha significado el tránsito de un modelo centrado en el Estado, con alta gravitación del sistema de partidos en la mediación con la sociedad, hacia otro en el que se enlazan Estado, mercado y sociedad. En este nuevo escenario, sostendremos que el mercado opera como articulador preponderante, mientras la ciudadanía y los movimientos sociales (sin perjuicio de las rutas partidarias), plantean nuevas estrategias de confrontación en torno a la igualdad política y social, sin prescindir del mercado, pero sí contra él.

\section{América Latina en el nuevo siglo, escenarios sociopolíticos y acción colectiva}

América Latina en los últimos cuarenta años transitó desde rupturas institucionales en los años setenta, ajustes estructurales en las economías, de primera y segunda generación, en las dos décadas siguientes y los nuevos proyectos democráticos que se consolidan en los noventa, podemos destacar dos cuestiones claves que nos permiten comprender, respectivamente, lo que se conoce como el Estado postindustrial globalizado y la globalización neoliberal». Primero, las privatizaciones y las medidas de ajuste estructural de los años ochenta y noventa. Segundo, la consolidación del modelo extractivo-exportador que contribuyó a acentuar las brechas sociales entre los países del norte-centro y del sur-periferia, marcado por la explotación intensiva de los recursos naturales cada vez más escasos, la contaminación, la extensión del monocultivo y la consiguiente pérdida de biodiversidad. Todo ello con el objeto de satisfacer los crecientes requerimientos de materias primas desde el centro europeo-

7. REVilla (2005) p. 37. 
norteamericano y más recientemente desde las economías asiáticas y las mega sociedades con economías en expansión como la China ${ }^{8}$.

América Latina, particularmente, tras cerrar el ciclo de las dictaduras, se centró en las transformaciones estructurales que le impuso el «consenso de Washington» en los años ochenta (profundizadas bajo el «consenso de Santiago» en I $998^{9}$ ), con cambios que alcanzaron la organización económica y la estructura misma de los estados, lo que trajo como consecuencia el desempleo de grandes masas de trabajadores, «ensanchando la brecha entre ricos y pobres e informalizando la economía y la subsistencia popular» ${ }^{10}$.

Por su parte, los gobiernos democráticos no han estado a la altura de las expectativas de los nuevos ciudadanos latinoamericanos que, luego de la represión política, policial y la precarización social sufrida durante las dictaduras expandidas en casi toda Latinoamérica, aspiraban al mejoramiento sustantivo de sus condiciones de vida, tras décadas sumidos en la pobreza y la desigualdad social ${ }^{11}$. De esta forma se generó un fenómeno complejo, en que, por una parte, las florecientes democracias potenciaron a sujetos que paulatinamente se fueron articulando colectivamente en la búsqueda y demanda de una "nueva democracia», participativa, incluyente de sus capas populares históricamente marginadas y que además respondiera a los nuevos bríos de una diversidad que empezó a cobrar visibilidad y reclamar reconocimiento institucional. Mientras, paralelamente, los nuevos gobernantes no lograron, en general, consolidar modelos democráticos renovados, sino que reprodujeron las viejas estrategias de las democracias formales representativo-burguesas. Así, los gobiernos latinoamericanos se vieron inmersos en crisis de corrupción, prácticas clientelares, problemas de ineficacia e inoperancia, que potenciaron progresivamente la desconfianza en el sistema de partidos como medio articulador entre el Estado y la sociedad civil. Se configuró una crisis de la institucionalidad democrática misma, en que las movilizaciones sociales emergieron con el nacimiento del nuevo siglo en diversos estados, marcadas de radicalidad y decepción ${ }^{12}$. Han abundado los paros y cortes de ruta de los trabajadores y campesinos, las movilizaciones estudiantiles (emblemáticas en México y Chi-

\footnotetext{
8. GARCÉS (2003) p. 3 .

9. FAundes (2013) pp. 430-432.

IO. GARCÉs (2003) p. 3.

I I. MiRZA (2006) p. I3.

I2. MirzA (2006) p. I3.
} 
le); los piquetes y marchas de los desocupados (Argentina); ocupaciones de tierra, cuyo ícono son «los sin tierra» de Brasil; y sucesivos levantamientos de los indígenas en toda América Latina, desde México hasta Argentina y Chile. Ahora bien, como veremos, esta efervescencia no significó una derrota al sistema de mercado en la región.

\section{América Latina en la globalización del capital}

Paralelamente, los estados de América Latina se integraron a los procesos económicos globales en expansión, de lo que también dan cuenta los nuevos escenarios sociopolíticos de la región.

En un sentido general, la novedad de la globalizació $n^{13}$ radica en que el binomio «tecnología-energía fósil» aceleró exponencialmente todos los procesos: economía, comunicación, relaciones sociales, presión sobre el medio ambiente, etc., lo que repercutió directamente en la relación de las sociedades y estados nacionales como los latinoamericanos, frente a los nuevos sujetos o poderes de orden global que se fortalecieron en posiciones de poder dominante. Como lo describe Quijano, la globalización implica principalmente «una continua y rápida re-concentración de la autoridad pública mundial, en rigor una re-privatización del control de la autoridad colectiva» ${ }^{14}$. Entonces, una de las claves de la situación actual radica en que los países no desarrollados, periféricos, se hicieron dependientes y siguieron para sí un modelo de desarrollo capitalista definido por las sociedades industrializadas, quedando expuestos, sin posibilidades de adaptarse, controlados desde el centro en todos los campos, desde la producción económica (extractiva o industrial), hasta los modelos teóricos del conocimiento ${ }^{15}$. Las economías «subdesarolladas» integraron estos procesos basados en políticas de ajuste estructural impuestas por los grandes organismos económicos (FMI, Banco Mundial, OMC y otros). Incluso hoy observamos «nuevas periferias» del capital, más allá de las cercanías fronterizas, como las medidas impuestas para condicionar el «rescate» de Grecia y los ajustes exigidos al gobierno español, basados en despidos en el sector público, reducción de salarios y pensiones, entre otros aspectos principales.

En el ámbito americano, estas políticas globales focalizadas en el extracti-

I3. BECK (I998) p. 29.

I4. QuiJANO (2002) p. I3.

I 5. AMin (I995) p. I8. 
vismo a gran escala de los recursos naturales de los estados y sus comunidades locales, recurrentemente perjudicaron a los sectores más desprotegidos en el nivel nacional (pobres, mujeres, indígenas). En definitiva se configuró una soberanía erosionada, traducida en la des-nacionalización y des-democratización de los estados nacionales en las áreas no centrales del sistema capitalista ${ }^{16}$. Desde esta perspectiva la globalización implicó una pérdida de poder para los estados nacionales no centrales, en lo que se ha considerado «la desterritorialización de la política» bajo poderes de tipo económico que no han sido elegidos y no son representativos de comunidades políticas, pero que terminan siendo responsables de la estabilidad democrática estatal paralela al avance de la globalización ${ }^{17}$. Atilio Borón, los llama «los nuevos leviatanes», dada su escala planetaria y extraordinaria gravitación económica, social e ideológica ${ }^{18}$.

Una cuestión central de estos procesos de crecimiento e industrialización radica en que ocurren en relación con un mercado mundial centrado en mercancías, dinero y capital que tensiona un mundo finito, en que existen límites concretos y cada vez más absolutos, económicos, sociales y ecológicos, que determinan imposibilidades de realización para la fórmula de desarrollo industrial globalizada. Este fenómeno se conoce como las fronteras naturales o ambientales del crecimiento, el «límite de la naturaleza» ${ }^{19}$. De esta forma, la competitividad económica, el crecimiento y el aumento de la productividad, ejes programáticos de los gobiernos de los estados de base capitalista ${ }^{20}$, no son conciliables con la sostenibilidad social y ambiental, porque el modelo basado en el crecimiento expansivo, mediado o no con la regulación estatal, conduce a la crisis ambiental planetaria ${ }^{21}$.

$\mathrm{Al}$ mismo tiempo, las economías nacionales de base primaria exportadora, en general, son controladas por los flujos y la pérdida de valor relativo del capital que limitan determinantemente la capacidad de capitalización, para potenciar procesos localizados de industrialización.

I6. QUIJANO (2002) pp. I3-I4.

I7. Altvater y Mahnkopf (2006) p. 343.

I8. BORÓN (2000) p. IO3.

i9. Altvater y Mahnkopf (2006) p. 327; Altvater (2006) p. 357.

20. El modelo se ha expandido en la región, incluso en aquellos casos de gobiernos con discursos «anti neoliberales», como los de Correa en Ecuador y Morales en Bolivia.

2i. Altvater y Mahnkopf (2006) p. 307. 
En síntesis, la aspirada «industrialización» importada por los gobiernos de Latinoamérica (en buena medida impuestos), forzó y fuerza la aceleración de los procesos socioeconómicos, el "progreso técnico» presiona el consumo de recursos y la utilización de energía (especialmente fósil). Es la paradoja del crecimiento contra los límites de la naturaleza, ya saturada, que nos ha llevado a una crisis social de inequidad, nacional, regional y planetaria, indisoluble de la crisis ambiental global, las cuales podemos sintetizar como la "cuestión social» junto con la "cuestión ecológica» ${ }^{22}$.

En este contexto se fue reconfigurando un escenario político regional en que destacan las acciones antineoliberales, prácticas y discursos, acompañadas del ascenso al poder de nuevos gobiernos de izquierda, centroizquierda o "progresistas", que estimularon la posibilidad de pensar creativamente las articulaciones entre Estado y sociedad, entre democracia representativa y democracia directa y participativa, entre lo institucional y lo no-institucional ${ }^{23}$. Así, ya en pleno siglo XXI la matriz «Estado-céntrica» dio lugar a nuevos escenarios bajo una matriz "mercado céntrica», cuyos ejes son el mercado, el Estado y la sociedad civil ${ }^{24}$.

\section{Escenarios sociopolíticos de América Latina en el siglo XXI}

Podemos identificar, como tipos ideales, por lo menos cuatro contextos sociopolíticos, sin perjuicio que cada uno de los países, sus sociedades y gobiernos presentan su propia particularidad ${ }^{25}$.

Neoliberalismo de Guerra. Es un proyecto sociopolítico que supone la profundización de la matriz extractiva exportadora bajo control transnacional y de colonización político-económica capitalista, instalado y sostenido, inclu-

22. Altvater y Mahnkopf (2006) pp. 335, 362.

23. SVAmpa (2007) p. 6.

24. GÓMEZ (2012) p. I70-I72.

25. Sintetizamos, en general, tres grandes escenarios socio-políticos que proponen ZiBechi (2006a) p. 226, y TADDEI (20I2). En nuestro desarrollo conceptual seguimos a Emilio Tadei conforme las conferencias que dictó durante el Primer Semestre de 2012 para el Doctorado en procesos sociales y políticos en América Latina de la Universidad ARCIS, Santiago de Chile, pero, para efectos de las citas se referencia la obra colectiva de SEOANE, et al. (2OI2) pp. 28-32. Además agregamos un escenario (el segundo) propuesto por GómEZ (2OII). 
so, bajo un proceso de militarización de las relaciones sociales, orientado a disciplinar las clases y grupos subalternos. En este contexto los movimientos sociales mantienen una fuerte presencia en el escenario nacional (Colombia, México, Chile) y sus gobiernos son descritos como «Gobiernos neoliberales alineados con EE.UU».

En estas estas sociedades opera la matriz «mercado-céntrica». Encontramos tanto aquellas democracias representativas autoritarias, de restructuración capitalista neoliberal temprana e intensa, profundamente desiguales y fragmentadas. El caso de capitalismo neoliberal más avanzado es el de Chile. Le siguen los casos en que el neoliberalismo es dominante-aunque no hegemónico-como en México y Colombia. Y también están aquellas sociedades que muestran un proceso franco de trasformación neoliberal, como el caso Uruguayo ${ }^{26}$.

Neodesarrollismo. Comprende administraciones progresistas que siguen respondiendo al modelo neoliberal, pero que han recuperado la retórica del desarrollo, buscando reimpulsar cierta actividad industrial y recuperar la autoridad estatal, junto al reposicionamiento internacional, así como persiguen asegurar bases para su legitimidad en la recuperación del empleo y políticas sociales más fuertes y masivas. Se registra una potente fragmentación entre las organizaciones que forman los movimientos y en su seno mismo, dado por la disputa en el posicionamiento frente a los gobiernos (Argentina, Brasi ${ }^{27}$ ). Nosotros plantearemos desde una posición crítica que Bolivia, más allá de su discurso y constatadas sendas contradicciones incuba, más o menos intensamente, este modelo.

Neoliberalismo precario. Corresponde a aquellas sociedades en que la res-

26. Gómez (20II) pp. 63-65.

27. El año 2016 presenta sucesos muy relevantes que pueden reconfigurar los escenarios regionales, por lo que deben seguirse observando. El reciente fin de la «era Kirchner» y la llegada al poder de Macri, quien aplicó inmediatos ajustes de schoc, parecen redireccionar a Argentina hacia el primer grupo neoliberal exacerbado, pero ello requiere de una observación más extensa, para evaluar si Macri logra sortear la gran base industrial de la economía trasandina, junto a al poderoso Estado Argentino, siempre en tensión con los gremios que hoy se realinearon en oposición a su nuevo gobierno. La «caída» (suspensión) de Roussesf en Brasil también requerirá de seguimiento en el mismo sentido, a fin de establecer si solo ha habido un cambio (por ahora temporal) en la conducción política o podría ocurrir un giro que afecte el modelo de desarrollo. 
tructuración capitalista neoliberal aún no ha logrado profundizarse y en que las posibilidades de resistencia están todavía abiertas a soluciones no neoliberales, como ocurre en Centro América y el Caribe, excluyendo $\mathrm{Cuba}^{28}$.

Democracias contrahegemónicas. Se trata de sociedades que han avanzado en proyectos políticos de base popular que buscan romper con el modelo hegemónico neoliberal. En estos casos los gobiernos surgen en medida importante de las acciones de los movimientos o incluso han gobernado con ellos. Su fuerza reside en la acción de los sectores subalternos que plantean un horizonte de cambio social, introduciendo cambios estructurales a la institucionalidad. Aspiran a la transformación de la matriz liberal colonial del Estado, hacia una radical democratización (redistribución del poder, del ingreso y la riqueza) y la recuperación de los recursos naturales que habían sido apropiados. A ello se agrega un control público de los sectores estratégicos de la economía. Incluso algunos hablan de «Socialismo comunitario» ${ }^{29}$. En este caso los movimientos sociales han tenido un peso determinante, pero sus acciones y posiciones varían atendiendo a las diversas coyunturas políticas, mediante apoyo frente a los sectores que buscan la restauración neoliberal o la oposición cuando no ven cumplidas sus expectativas (Venezuela, Bolivia, Ecuador) ${ }^{30}$. Se trata de sociedades que han resistido al neoliberalismo más radical, pero no por ello emancipadas del capitalismo. En este sentido, ni los movimientos sociales que dan lugar a la «Revolución Bolivariana» en Venezuela («caracazo»), ni el proceso

28. Gómez (20II) p. 63.

29. Si bien, podemos decir que hay expresiones de «socialismo comunitario", SEOA$\mathrm{NE}$, et al. (2012) p. 30, presentes en algunas de las sociedades que se proponen para esta categoría, no nos parece que esté en todas ellas, ni siquiera en la boliviana que figura como la más avanzada socialmente.

30. TADEI (20I2) plantea algunas dudas respecto de Ecuador. En nuestra opinión, teniendo claro que hay diferencias histórico-temporales relevantes entre el proceso contra hegemónico cubano y los procesos de Ecuador, Venezuela y Bolivia, en particular el hecho que se trata de un régimen político, a lo menos, con déficit democrático, Cuba podría incluirse en este cuarto grupo. Esto es razonable dado que los sectores subalternos, en su momento histórico, generaron un cambio radical en las estructuras de acumulación, la hegemonía del poder y la institucionalidad. A su vez, queda por evaluarse los impactos en el modelo de desarrollo cubano del sostenido proceso de apertura económica liderado por Raúl Castro. Al respecto, el restablecimiento de relaciones diplomáticas entre Cuba y Estados Unidos (2015), sin duda, ha acortado brechas, por lo menos ideológicas, con el neoliberalismo. 
constituyente boliviano (2000-2009), cuestionaron el sistema representativo neoliberal, por el contrario, utilizaron todos los mecanismos de la desgastada democracia representativa venezolana o la pactada de Bolivia, para generar la transformación radical del régimen político imperante. Ejemplifica este tipo de conflicto el caso de la «Guerra del Agua» en Cochabamba, que pone en movimiento los elementos de la matriz «Estado, mercado y sociedad» ${ }^{31}$.

Este escenario general presenta peculiares características respecto de los estados con gobiernos de mayor base popular, también llamados «de izquierda» o «progresistas», porque los movimientos sociales han debido abordar y poner en práctica estrategias inéditas, replanteándose sus propios objetivos, para enfrentar gobiernos que han alcanzado el poder desde los propios movimientos o mediante coyunturas creadas por ellos ${ }^{32}$. En estos casos lo frecuente es que la movilización impulse los cambios, más allá de lo más o menos progresista de un gobierno determinado. Sin embargo, algunos movimientos se han visto atrapados en una suerte de dilema en tanto sienten un grado de identificación con los gobiernos que han ayudado a instalar o incluso del que de una u otra manera, forman parte. Así, aparece el caso del MAS en Bolivia, movimiento social que tiende a institucionalizarse y para algunos se ha transformado en partido político (de gobierno).

Asimismo, en los casos de cambios constituyentes de democratización (como Ecuador, Bolivia y en alguna medida Venezuela ${ }^{33}$ ), las elites locales e internacionales siguen teniendo poder por lo que los movimientos y los gobiernos populares interactúan bajo la permanente tensión o amenaza de la restauración ${ }^{34}$. Los sectores conservadores, que siguen controlando los grandes capitales, presionan y desgastan a los gobiernos que introducen reformas sociales, mientras los actores sociales se mueven entre el apoyo crítico y el rechazo mismo a los que suponían «sus gobiernos». Pragmáticamente — como concluye Zibechi-,

3 I. GÓMEZ (20II) p. 64-65.

32. ZibeChi (2006a) pp. 226-227.

33. Hacemos presente que es muy difícil caracterizar a Venezuela tras la muerte de Chávez porque, si bien el gobierno de Maduro ha debido sortear los esfuerzos restauradores de la oposición de la derecha económica que ha buscado derrocar el régimen chavista, con abierto apoyo estadounidense, también está claro el derrotero autoritario y la crisis política de la que es responsable el propio régimen venezolano actual y que llevó a que la OEA le aplicase la Carta Democrática en 20 I 6.

34. García Linera (20I I). 
amplios sectores de las sociedades latinoamericanas parecen estar asumiendo que un escenario aceptable consiste en la continuidad de administraciones progresistas a las que siempre es necesario, posible y efectivo presionar para ir alcanzando gradualmente, con mayor o menor intensidad, los cambios demandados, antes vedados por los gobiernos autoritarios. El MST (Movimiento de los Sin Tierra), los movimientos sociales bolivianos, ecuatorianos y uruguayos responden a esta tendencia ${ }^{35}$.

El caso de Bolivia muestra cómo el gobierno de Evo Morales oscila entre la alianza con los movimientos y las concesiones a la derecha económica, para no quedar atrapado por la efervescencia popular que, tanto reconstituyó al país, como lo desgobierna ${ }^{36}$. Así, es la propia ciudadanía la que rechazó una cuarta reelección consecutiva de Evo Morales en febrero de 20I6, abriendo posibilidades inciertas hacia los próximos escenarios.

Por su parte Garretón, plantea una categorización relativamente diferente para los escenarios en la región, sobre la base de dos grandes modelos en disputa, «derecha» $\mathrm{y}$ «centro izquierda o de izquierda» y respectivas variantes en tensión en la recomposición de la relaciones Estado-sociedad. Unas sociedades responden desde la política (populista o político partidaria), como Venezuela, Argentina, Chile, Uruguay; mientras otras que disputan esta recomposición desde la sociedad civil, como Bolivia. Por último, identifica una recomposición desde los propios mercados regulados por el Estado, en que las políticas públicas económicas remplazan «la política», lo que denomina «el modelo tecnocrático», propio de los gobiernos y partidos de una «nueva derecha». En este sentido, enfatiza que lo que está en juego es la «reconstitución de comunidades políticas» versus las fuerzas que «quieren imponerse como naturales y metasociales, de la economía y del mercado ${ }^{37}$.

Como veremos más adelante, la perspectiva de Garretón, apunta más bien a los esfuerzos por recomponer una matriz que sigue ubicando a los partidos políticos como ente mediador con el Estado y al mercado como antagonista político. Mientras, en la lectura «mercado-céntrica», se asume al mercado en una posición articuladora de las relaciones sociales, como presupuesto para el estudio y mejor comprensión del conflicto social y la acción colectiva en América Latina.

35. ZiвеCHi (2006a) pp. 226-227.

36. ZibeChi (2009), pp. I89-I9I.

37. Garretón (2012) pp. 64-67. 


\section{La Acción Colectiva y los «nuevos» movimientos sociales en América Latina}

Manuel Antonio Garretón define los movimientos sociales «como acciones colectivas con alguna estabilidad en el tiempo y algún nivel de organización, orientadas al cambio o conservación de la sociedad o de alguna esfera de ella». Luego explica que conforme esta definición la noción de movimiento social oscila en dos polos teóricos. Por una parte, «la visión de una acción colectiva que responde a tensiones o contradicciones específicas y que se orienta a resolver esa contradicción específica»; y, por otra, «la visión del movimiento social como portador de un sentido de la historia y la encarnación, como agente fundamental del cambio social ${ }^{38}$. De esta forma, propone la «acción colectiva» y el «movimiento social» como dos dimensiones de los movimientos sociales. Así, el «movimiento social» (en singular) se orientará al nivel «histórico-estructural de una determinada sociedad, definiendo su conflicto central». Mientras, los «movimientos sociales» (en plural) corresponderán a «actores concretos que se mueven en los campos de los mundos de la vida, organizacional o institucional, orientados hacia metas específicas y con relaciones problemáticas, que se definen en cada sociedad y momento» ${ }^{39}$. Deja también en claro, como veremos, que «los movimientos sociales son un tipo de acción colectiva y no el único» ${ }^{40}$. De esta forma, en las líneas siguientes nos abocaremos a revisar cuáles son las características que nos permiten hoy hablar de «movimientos sociales» en América Latina, presentando una síntesis de los principales conceptos y relativos concesos teóricos en torno a ellos ${ }^{41}$.

El proceso de la acción colectiva es un proceso de construcción de identidades colectivas que es siempre un proceso interactivo y comunicativo:

Los actores sociales, al definir la identidad, se definen a sí mismos y sus relaciones con otros actores de acuerdo con los recursos disponibles y con las oportunidades y restricciones del medio.

38. Garretón (200I) p. I4.

39. Garretón cita, como autor clásico de la primera línea teórica a N.J. Smelser Theory of Collective Behavior, "Free Prees, New York», I962; y para la segunda corriente refiere a A. Touraine, "La voix et le régard», Paris I978, GARretón (200I) p. I4.

40. GARRETón (200I) p. I4.

4I.Véanse: Revilla (I996; 20IO) pp. 55-56; GARRetón (200I); Goicovic (I996; I998). 
Esta acción implica otros actores, recursos, capacidades organizativas, habilidades de liderazgo, circunstancias coyunturales y condiciones estructurales. Esos procesos configuran escenarios en los que se hace posible o no la acción colectiva y en los que se condiciona la forma que adopta la acción.

Vinculo central entre acción colectiva y acción individual. La dimensión individual de la acción colectiva interesa en la medida en que los individuos constituyen los sujetos colectivos, atribuyen significados a su acción, se reconocen en los otros y con los otros y llevan a cabo actos intencionados. Es decir, hay un vínculo necesario entre acción colectiva y acción individual. En consecuencia, las relaciones intersubjetivas de reconocimiento y la interacción de los sujetos y sus grupos están en la base de la construcción democrática misma, porque - siguiendo a Lechner- el miedo al otro se teje constantemente en nuestras sociedades y nos exige reformular los códigos interpretativos para abordar una política que fije trayectorias para «los ciudadanos que buscan su lugar como partícipes del mundo común ${ }^{42}$. En este sentido expresa Lechner que la modernización, rica en transacciones, no genera necesariamente lazos sociales, «los procesos de secularización, diferenciación, y mercantilización de la sociedad moderna, potenciados por la globalización, socaban las identidades colectivas». Consecuentemente, las situaciones de incertidumbre, contingencia y desorientación, hacen "surgir sentimientos de abandono y desamparo", más el miedo al otro, a la exclusión, al sinsentido, que «condicionan nuestras expectativas acerca de qué puede y debe producir un orden democrático", desestabilizando el propio orden. Sentencia finalmente que el diálogo colectivo en torno a dichos «miedos es un ejercicio de democracia», porque solo logrando compartirlos somos capaces de enfrentarlos ${ }^{43}$.

Surge entonces la necesidad en los movimientos sociales de una nueva articulación de relaciones éticas, políticas y jurídicas, que recíprocamente permitan a los sujetos valorar a los otros con quienes están socialmente en interacción, individual o colectivamente ${ }^{44}$.

La acción colectiva implica la articulación de intereses compartidos. La acción colectiva corresponde a «individuos que actúan conjuntamente para el logro de intereses comunes», existiendo "un conflicto entre el interés individual y el interés colectivo», por lo que el éxito y proyección en el tiempo de

42. LECHNER (2002) p. 46.

43. LECHNER (2002) pp. IO, 46.

44. HONNETH (I997), p. I 57. 
la movilización estará mediado por la cohesión del grupo, entendido como el grado de coincidencia entre los intereses individuales y el interés colectivo, como una «la identidad compartida» por las redes internas de un grupo. Así entonces, aunque con el paso del tiempo los individuos componentes de un movimiento social cambian porque se producen diversas dinámicas, como los recambios generacionales, si se mantiene nuclearmente el mismo conjunto de creencias, el movimiento social puede pervivir ${ }^{45}$.

Con todo, frente a los fenómenos de identificación colectiva se plantean dos reservas: una, en torno al pluralismo político cómo límite a los procesos identitarios de orden cultural radicales ${ }^{46}$; y otra, en cuanto la total identificación («suturación») en un grupo es imposible frente a la «indeterminación» siempre presente en las relaciones sociales ${ }^{47}$.

Los movimientos sociales encarnan un "proyecto político». Un movimiento social se configura cuando logra transitar desde «expresiones de movilización social popular» (marchas, protestas, motines, tomas de fundos, etc.), hasta encarnar un proyecto político ${ }^{48}$. $\mathrm{Y}$ este no es un proceso espontaneo, sino que de la noción de «identidad» surge la idea de un proyecto político que deberá ser capaz de transformar al sujeto, como proyecto que se encarna en él, dialécticamente, dando nuevas formas al sujeto y al proyecto político colectivo al mismo tiempo ${ }^{49}$. En este sentido, nos dice Luis Tapia que un movimiento social

45. ReVilla (I996) pp. I7-I8.

46. Garretón rechaza el «movimientismo identitario que elimina el pluralismo y la existencia del otro", (2004b) p. 95. De nuestra parte no vemos en los procesos identitarios -a lo menos de los pueblos indígenas latinoamericanos- un riesgo para el pluralismo y la democracia, por el contrario, consideramos que los esfuerzos interculturales avanzan hacia el reconocimiento del «otro» (colectivo) como un sujeto tan válido como "yo» (individual), todo lo cual asienta las relaciones de convivencia social. En este sentido, véase las críticas a Jürgen Habermas (I999) de Magdalena Gómez (2002) y Juan Jorge FAundes (20I 5 a; 20 I 5 b). Entre otros, recogen en América Latina un enfoque «intercultural» para las relaciones de reconocimiento y la conformación de identidades culturales y colectivas: Fornet-Betancourt (2007; 20 I I); Domingo (20I I), Claros y Viaña (2009) y SAlas (2003). Con diferencias relevantes respecto de los anteriores, en la tradición central multiculturalista, véase: TAYLOR (I992) y KimlyCa (I995; 2009).

47. LACLAU (2005).

48. Goicovic (I996) p. 3.

49. Reguillo (200I). 
politiza los espacios sociales, las demandas, discursos, prácticas y proyectos. El movimiento comienza a configurarse cuando la acción colectiva cuestiona «los criterios y formas de distribución de la riqueza social o de los propios principios de organización de la sociedad, del Estado y del gobierno ${ }^{50}$.

Al mismo tiempo, siguiendo a Garretón, estos proyectos han dejado, en general, de definirse en torno a un proyecto social central - podemos decir nosotros un "proyecto político central»- para asociarse en torno a diversos ejes que devienen de procesos de democratización política, social y afirmación de identidades. Se trata de múltiples proyectos en referencia a múltiples subjetividades colectivas, pero articuladas, «actores concretos que se mueven en los campos de los mundos de la vida, organizacional o institucional, orientados hacia metas específicas» conforme problemáticas que se definen en cada contexto social ${ }^{51}{ }^{52}$

La acción colectiva tiene una fase de «movilización» y una fase de «latencia». Dice Revilla — siguiendo a Melucci-que el aspecto visible, la «movilización» es sólo un momento, una faceta del movimiento social, porque el aspecto central «es la interconexión de los individuos involucrados en el proceso de

50. TAPIA (2009) p. 2.

5 I. GARretón (200I) pp. 39, I4.

52. Esta característica, a modo de ejemplo, la podemos visualizar con claridad en dos casos. En Chile, el movimiento estudiantil que cuestionó el modelo educativo mercantilizado, bajo una educación pública reproductora de las exclusiones sociales. Con diversos momentos, segmentos, grupos y repertorios de acción (con sus hitos 2006 y $20 \mathrm{II}$ ), ha luchado hasta hoy (20I6) interpelando a la institucionalidad política y económica, que se vio obligada a impulsar una reforma educacional que, a su vez, requirió una «reforma tributaria» (o al menos un ajuste). Frente a ella, siguen resistiendo porque, precisamente — sostienen - el conjunto de medidas institucionales no han alcanzado (entre otras cuestiones) la gratuidad universal y solo se reformulan mecanismos que facilitan el lucro en la educación superior, sin modificar las brechas de la desigualdad social y la pobreza estructural, fin último de la demanda por la reestructuración educativa. Asimismo, en medida importante, este movimiento estudiantil que en diversas faces temporales ya cumple una década, potenció el actual proceso constituyente «institucional» chileno (más allá del real impacto de éste). En Bolivia, un movimiento social local, como la "Guerra del Agua» en Cochabamba (2000), dada la trascendencia de su demanda y el profundo sentido de justicia social que arraigaba, terminó desencadenando el proceso constituyente que llevó al actual Estado Plurinacional (2007-2009) y su nueva Constitución (20II). 
identificación, su trabajo autoorganizativo de producción del mapa cognoscitivo que le caracteriza como código distinto a otros códigos culturales». Esta aclaración le permite distinguir entre las fases de «latencia» y «visibilidad», oportunidades, respectivamente, de "producción de sentido y movilización como demostración de las propias señas de identidad». La distinción permitirá dar cuenta de la persistencia del movimiento social más allá de sus demostraciones o movilizaciones con ocasión de fenómenos o conflictos determinados ${ }^{53}$.

Las acciones de movilización constituyen lo visible, sin embargo, la definición de las formas de protesta o «repertorios de la acción ${ }^{54}$ debe estudiarse inmersa en los procesos políticos, sociales y culturales de que son parte, la fase de latencia. Para que los trabajadores, obreros o campesinos, los ciudadanos y las ciudadanas en general, lleguen a movilizarse en algún episodio concreto de acción, es necesario que exista organización, comunicación, identidad, liderazgo, intercambio, etc. ${ }^{55}$.

En resumen, vamos a considerar la configuración de un movimiento social frente a la conjugación ideal de los siguientes elementos.

La acción conjunta de individuos, ejecutada mediante acciones coordinadas, para alcanzar un fin común, motivado por intereses comunes que comprende un proceso de identificación individual y un proyecto político.

De esta forma, podemos plantear que cualquier movilización social o acción colectiva no es un movimiento social, aunque puede estar en las bases de su conformación. Como previene Goicovic, la distinción radicará en «la construcción del puente entre la acción colectiva y la proyección política» ${ }^{56}$. Es decir, un movimiento social, si bien desestabiliza, persigue, en último término,

53. Revilla (I996) pp. I2-I3.

54. Los «repertorios de la acción» corresponden a lo que los participantes hacen cuando están inmersos en un conflicto contra otros y pueden ser de diversa naturaleza y alcance: acciones aceptadas por las autoridades de escaso riesgo (mítines, campañas políticas, propaganda, manifiestos, firma de peticiones, manifestaciones, marchas y huelgas); acciones que consideran la alteración del orden público e incluso incluyen el uso eventual de la violencia (daños contra la propiedad, huelgas de hambre, campañas de desobediencia civil, boicots, ocupación de edificios, bloqueos del tráfico o pintadas); y repertorios «de violencia» para fines políticos (la lucha armada y el terrorismo). ReVilla (20IO) pp. 55-6I.

55. ReVilla (20IO), pp. 57-6I.

56. Goicovic (I996) p. 8. 
una reconfiguración de las fuerzas, de la política y del Estado. Aunque el objetivo último de los movimientos sociales dejó de ser la lucha por el gobierno o el poder del Estado mismo (aunque no se descarta como ocurrió en Bolivia), sí plantea una demanda frente al Estado y también en la sociedad civil ${ }^{57}$, cuya radicalidad, al final de la ruta, puede conducir a la redefinición de las relaciones sociales, en mayor o menor profundidad. De esta forma, no será posible separar absolutamente, la conexión entre las acciones colectivas, las demandas, movilizaciones y articulaciones de los nuevos movimientos sociales, como expresión de la sociedad civil, con la construcción de los nuevos entramados institucionales y las nuevas tensiones con el mercado ${ }^{58}$ con las cuales se confrontan estos movimientos.

\section{Ejes del conflicto social y nuevos movimientos sociales en América Latina}

Una característica gravitante del contexto social y político latinoamericano del siglo XXI, es el tránsito que se produce en la composición misma de los movimientos sociales, perdiendo protagonismo el movimiento obrero, como movimiento social central, lo que facilitó el surgimiento de nuevos sujetos sociales y nuevas prácticas de movilización social ${ }^{59}$. Según explica Garretón al desarticularse la relación entre Estado y sociedad que privilegiaba la dimensión política del conflicto social, los actores sociales transitan paulatinamente «de actores básicamente económico-políticos y centrados en el nivel histórico estructural de las sociedades, a actores definidos socioculturalmente» que definen identidades en «referencia a los mundos de la vida (subjetividades) ${ }^{60}$. Se relevaron así otras problemáticas como la exclusión de los pueblos indígenas; el rol de la mujer en la sociedad y en la propia movilización colectiva; junto a la crisis ambiental y la apropiación de los bienes comunes y de la naturaleza.

Los procesos de redefinición de la ciudadanía y las nuevas formas de exclusión, han generado nuevas formas de acción colectiva, diferenciadas de las clásicas, centrales, que requieren otras formas de representación y espacios de institucionalización que den lugar, tanto a las formas clásicas, como a las

57. SANTOS (2004).

58. GÓMEZ (2OI2).

59. SANTOS (200I) p. I77.

6o. Garretón (200I) pp. 39-40. 
emergentes que deben ser canalizadas por «la política y sus actores» ${ }^{61}$. Pero, como veremos, nos cuesta apreciar cómo podría ser realizada esta tarea por la «política institucionalizada» que es, precisamente, la que ha entrado en crisis, la misma que con su debilitamiento estaría potenciando la emergencia de los movimientos sociales en América Latina. Por ello, consideramos que las demandas, estrategias, formas de acción y conquistas de los nuevos movimientos sociales latinoamericanos exigen una revisión del marco de análisis ${ }^{62}$. Al efecto, siguiendo a Mirza, podemos identificar cuatro ejes en los que se mueve la acción colectiva: la democratización política; la democratización social apoyada en la revalorización de los derechos sociales y de ciudadanía; la reconstrucción de las economías nacionales y su inserción en el proceso de globalización (neoliberal); y la reformulación de la modernidad en que se combinan la «racionalidad científico-tecnológica» ${ }^{63}$. Esta diferenciación, por una parte, configura los grandes campos o ejes en los que interactúa, emerge y se retrae, la acción colectiva, pero no son los respectivos proyectos de los movimientos sociales, porque cada uno de ellos traza sus propios horizontes, rutas y estrategias.

Ya no se trata de «un conflicto central», sino de demandas múltiples, diversas y hasta dispersas (que pueden incluir las antiguas aspiraciones obreras), pero que paralelamente han ido generado un proceso de «universalización» que apunta hacia la inclusión y una redefinición de la ciudadanía. Como señala Boaventura «si en algunos movimientos es discernible un interés específico de un grupo social (las mujeres, las minorías étnicas, los habitantes de las favelas, los jóvenes), en otros, el interés es colectivo y el sujeto social que los titula es potencialmente la humanidad en su todo». Lo observamos, por ejemplo, en el movimiento ecológico-pacifista que lucha por los valores de la cultura y la calidad de vida, que son, por sí mismos, universales y globalizantes» ${ }^{64}$.

Sin perjuicio de su heterogeneidad y dinámica constante, en los siguientes párrafos proponemos una breve tipología ideal de los diversos proyectos de los movimientos sociales latinoamericanos.

Los nuevos movimientos sociales involucran y promueven procesos de reafirmación de la identidad y la redefinición de la "ciudadanía», mucho más allá de las demandas de los respectivos colectivos. Constituyen una toma de

\footnotetext{
6I. Garretón (200I)p. 88.

62. Mirza (2006) p. 2 I.

63. Mirza (2006) p. 52.

64. SANTOS (200I) p.I79.
} 
conciencia de la exclusión que muta hacia la propia revalorización, como descolonización y cuestionamiento de la falsa ciudadanía ofertada por los estados post coloniales que fue fundada en un «Estado de Derecho» instituido por las elites - la «igualdad» de unos pocos ${ }^{65}$. Entonces, la demanda por una redefinición de la ciudadanía, inclusiva de la diversidad emergente, adquiere un rol aglutinante del conjunto de las respectivas demandas dispersas y coexistentes. La marginación de la ciudadanía impuesta de facto parece motivar la construcción de proyectos alternativos desde el lugar que ocupan, sin perder su identidad, una nueva forma de entender la ciudadanía horizontal e inclusiva.

Los nuevos movimientos sociales se sostienen también desde la revalorización y la recuperación de la cultura, afirmando la identidad de sus pueblos y sectores sociales históricamente excluidos como mujeres e indígenas.

Los nuevos movimientos sociales interpelan la privatización de la relación sociedad-naturaleza, propia de la globalización neoliberal. Van a poner en cuestión la racionalidad neoliberal. Tensionan el mercado y la «sociedad del consumo» que busca la apropiación de todo y de todos como objetos mercantiles, disgregados, no situados (naturaleza y cuerpo, hombre y mujer, trabajo y cultura ${ }^{66}$. Como prescribe Zibechi, «aún en los casos en los que la lucha por la reforma agraria o por la recuperación de las fábricas cerradas aparece en primer lugar, los activistas saben que la propiedad de los medios de producción no resuelve la mayor parte de sus problemas ${ }^{67}$. Este presupuesto va a significar una diversificación de los espacios de acción y de los fines mismos, una redefinición de la relación social con la naturaleza que llevará a que se planteen propuestas como la de un «buen vivir», versus conceptos como el de «desarrollo»y, en general, emergerán procesos contra hegemónicos que demandan la emancipación de todo aquello que había sido apropiado.

La autonomía aparece como un gran eje que sostiene los nuevos movimientos sociales, los cuales mediante diversas estrategias, como la conformación de redes, plataformas y otras articulaciones, han potenciado sus capacidades y aumentando su legitimidad respecto de la sociedad civil, distanciándose de la política tradicional ${ }^{68}$. Han logrado caminar cada vez hacia una mayor autonomía, tanto respecto de los estados, como de los partidos

65. ZiBECHI (2003) p. 86.

66. ESCOBAR (2003) p. 77.

67. ZiBechi (2003) p.I 87.

68. MiRZA (2006) pp. 25-26. 
políticos (que podemos llamar autonomía «institucional» o política). Este proceso se logra consolidar, sobre la base de la creciente capacidad que han desarrollado para asegurar la subsistencia de sus bases (autonomía material). Por lo tanto, las luchas de los nuevos movimientos sociales no se agotan o limitan en las coyunturas económicas ni en la contingencia política, pudiendo generar alternativas emancipatorias y de construcción democrática situados desde su propia identidad y procesos. La autonomía política se disputa con el Estado (también con las ONG en los países en que tienen mayor incidencia) que en lo esencial implica una forma diferente «plebeya»o «desde abajo» de hacer política. Todos los movimientos emancipatorios plantean alternativas a la política elitista tradicional, como otras maneras de construir democracia, aunque este camino deja abiertos muchos desafíos porque esta política abierta es mucho más incierta que la política institucional predominante ${ }^{69}$. La autonomía material implica emanciparse de la dependencia con el modelo, asumiendo la propia subsistencia como paso necesario para la resistencia, al menos en una parte. Producir y reproducir las vidas de modo diferente al mercado capitalista (los alimentos, la salud, el intercambio) ${ }^{70}$. Parece ser la más compleja de las dimensiones de la autonomía, porque «sin autonomía material las otras se desvanecen ${ }^{71}$. Se trata de no ser contraparte del asistencialismo o, derechamente, no esperar las soluciones desde el mismo sistema neoliberal al que se cuestionan la pobreza y la exclusión. Esta autonomía implica un proceso de introspección, se construye en la «fase de latencia» ${ }^{72}$ y supone una invisibilización de los movimientos durante un tiempo, pero «es la condición para construir una agenda propia que no sea calco ni copia de la agenda impuesta desde fuera ${ }^{73}$. Los movimientos sociales apuestan a la reconstrucción de una nueva democracia o al menos «generan las reservas energéticas para tal objetivo ${ }^{74}$ ». Ejemplos son los cocaleros bolivianos, los

69. ZiBECHI (2006b) p. 48 I.

70. Como ocurrió en Buenos Aires, en que algunos grupos piqueteros se organizaron para producir alimentos, ofrecer atención de salud y diversos talleres. "Sorprende que en plena ciudad, en el corazón del capital, hayan podido abrir espacios, aún débiles e incipientes, pero reales», ZiвECHI (2006b) p. 482.

7I. ZibeCHi (2006b) p. 482.

72. Revilla (2010).

73. ZibeCHi (2006b) pp. 48I-482.

74. Mirza (2006), p. 52. 
«campesinos Sin Tierra» en Brasil, los Piqueteros y los desocupados urbanos argentinos ${ }^{75}$.

Paralelamente, es posible apreciar una «emergencia femenina», un nuevo papel de las mujeres, con nuevos espacios conquistados por y para las mujeres en los movimientos y particularmente en sus dirigencias, ya no solo en relación a las demandas propiamente feministas, sino en general como integrantes activas de los nuevos actores sociales y su abanico de demandas. Su inclusión en los nuevos movimientos sociales constituye en sí misma una nueva forma del liderazgo y una expresión de profundización democrática, mientras las mujeres participan de las luchas de los movimientos por la democratización de sus sociedades. La mujer participa de un despliegue para la apertura de la ciudadanía y por la expansión de la ciudadanía ${ }^{76}$. Por ejemplo, en relación a la mujer indígena ${ }^{77}$, las formas de la inclusión y la emergencia femenina en la movimientalidad va más allá de los roles «re-productivos» que se le han reconocido tradicionalmente. Hablamos de un tránsito desde las actividades familiares de reproducción de la identidad cultural (la lengua, vestimenta, salud, etc.), pasando por el comercio que encontramos en los mercados y las calles latinoamericanas, hasta su inserción en los espacios político participativos, comunitarios, comunales, logrando un progresivo despliegue político y movimiental ${ }^{78}$.

La nueva movilización colectiva contiene un recambio y complejización en su base social, con una importante inclusión de las «clases medias». Los sectores medios que se vieron precarizados en sus derechos sociales, asumen un mayor involucramiento en cuestiones antes delimitadas a los sectores obreros, pero al mismo tiempo han sido potenciados como "nuevos consumidores». Surge así una nueva fuerza de trabajo heterogénea asociada a los nuevos entramados de la expansión neoliberal, pero que ya no tiene las mismas formas, no sigue las estrategias y marca un desapego -incluso en los imaginarios- con el

75. Zibechi (2003) p. I 86.

76. Zúñiga (2009).

77. Véase: KetTerer (20I I); Barragán (2006); CEIMM (2002); Calfío y VelasCO (2005); Escarárzaga (2006); Rivera y Borragón (I997); Rivera (2004).

78. Como describe Zibechi, «mujeres indias se desempeñan como diputadas, comandantes y dirigentes sociales y políticas; mujeres campesinas y piqueteras ocupan lugares destacados en sus organizaciones", estableciendo nuevas relaciones entre los géneros en las organizaciones sociales y territoriales que emergieron dentro de los nuevos movimientos sociales, ZiBECHI (2003) p.I 87. 
sindicalismo de las décadas pasadas. Estos nuevos movimientos sociales constituyen grupos sociales transclasistas que identifican nuevas formas de opresión y postulan un nuevo paradigma social que no se centra en el bienestar material, pero sí en la calidad de vida. Denuncian "con una radicalidad sin precedentes los excesos de la modernidad, el modo como se trabaja y produce; como se descansa y vive» ${ }^{79}$.

En esta nueva conformación trans-social los sectores medios, con toda su heterogeneidad, han pasado a ser un actor en muchos casos fundamental de la movilización social, aunque no por ello menos complejo de $\operatorname{articular}^{80}$. Particularmente, en los países con los gobiernos que describimos como de corte neoliberal más ortodoxo alineados con el modelo hegemónico, son estos sectores medios, más dotados de recursos para la acción, los que toman conciencia, dejan de tolerar y comienzan a desalinearse desde el núcleo mismo del sistema. Como dice Boaventura: «viven sin duplicidad y con igual intensidad la hegemonía del mercado y la lucha contra él ${ }^{81}$. Las demandas de emancipación social se entrecruzan con los reclamos de "consumidores» que exigen derechos como tales ante el «abuso» del Mercado pero que no buscan, necesariamente, un cambio de la «sociedad de consumo» misma.

En esta particular emergencia intersocial podemos distinguir, por ejemplo, las movilizaciones contra el «corralito» y el «que se vallan todos» en Argentina el 200I; la «rebelión forajida» en Quito el $2000^{82}$; las movilizaciones por una «educación para todos en Chile» el 20II. También, un buen ejemplo

79. SANTOS (200I) p. I78.

80. En este sentido, Laclau y Mouffe — revisando la visión de Gramschi- cuestionan la pertinencia actual del concepto de «clase» como bloque histórico, para proponer solo la posibilidad de conformar «articulaciones hegemónicas» enmarcadas en una heterogeneidad de sujetos o actores sociales ("posiciones de sujeto») que no tienen un devenir histórico asegurado, como una variedad de "puntos de ruptura y antagonismos democráticos» que pueden llegar o no a configurar un discurso hegemónico, LACLAu y Mouffe (2004) pp. 99-I26. Así, estos autores critican las teorizaciones sobre la naturaleza de los movimientos sociales, tanto como nuevos sujetos "privilegiados» frente al cambio social, o bien, como "sustituto revolucionario" de la clase obrera, Laclau y Mouffe (2004) pp. I25-I26. En Faundes (2015c) puede revisarse en mayor profundidad un análisis desde Laclau y Mouffe sobre la democracia (pluralista e intercultural) para América Latina.

8I. SANTOS (200I) p. I.

82. ReVilla (2010) pp. 63-64. 
de la transversalidad social de las articulaciones políticas presentes en estas nuevas expresiones de movilización, es aquel del alzamiento conocido como "Aysén, tu problema es mi problema», en Chile el 2012. Esta movilización, de una profunda raíz local, cruzó los diversos estratos sociales en sus demandas, donde campesinos, colonos (hacendados de origen inmigrante), trabajadores y pescadores artesanales, compartieron la calle con profesionales, funcionarios públicos e incluso pequeños comerciantes ${ }^{83}$.

En otra característica relevante, a diferencia de los partidos y de los movimientos obreros, la acción colectiva emancipatoria latinoamericana evita la organización jerarquizada, con división de tareas entre quienes dirigen y ejecutan, en la que los dirigentes se disocian de sus bases. Estos movimientos sociales tienden a reproducir la vida cotidiana, familiar y comunitaria, relevando la autoorganización y la autonomía territorial ${ }^{84}$.

Finalmente, en estos movimientos la comunicación y las redes sociales tienen un rol estratégico. Los nuevos movimientos sociales desarrollan la capacidad para llamar la atención mediante acciones atractivas y efectivas que se difunden a través de los medios de comunicación y las redes sociales ${ }^{85}$. En este contexto, la globalización tecnológica y las redes sociales -con un alcance difícil de dimensionar-, permiten la interconexión y articulación de movilizaciones en forma prácticamente instantánea. Aunque, al mismo tiempo, estas redes no permiten asegurar la existencia de relaciones interpersonales de cohesión. Por ello, se suele visualizar grupos masivos comunicados, articulados y dispersos a un mismo tiempo ${ }^{86}$.

83. Tenemos claro que en todos estos casos no podemos hablar siempre de «movimientos sociales» bajo los elementos del concepto que nos hemos dado previamente, pero los ejemplos refieren, más bien, a un esfuerzo por destacar la nueva composición de la movilización social, más allá de su capacidad, exitosa o no, de instalar proyectos colectivos y generar los cambios demandados.

84. ZibeCHI (2003) p. I 87.

85. Revilla (2010) p. 62.

86. El estudio en profundidad de este fenómeno escapa al análisis propuesto, aunque su revisión será central para completar las perspectivas de análisis de las relaciones Estado mercado y sociedad. Desde ya, entre otros, véase: CASTElls (2OI2); SCHERERWarren (2005); BAROZet (2003); CÁrdenas (2014); Martins (2009). 


\section{Crisis de la institucionalidad democrática y del sistema de partidos políticos en América Latina}

Un aspecto central del contexto sociopolítico y de la acción colectiva descrito, es el debilitamiento de la institucionalidad democrática, particularmente en las formas representativo delegatorias (que previamente se habían venido reforzando a la par del sistema neoliberal). El sistema de partidos políticos, en particular, enfrenta duros cuestionamientos, dando cuenta de su agotamiento, lo que se vio plasmado en los casos que la movilización social gatilló procesos constituyentes (Bolivia, Ecuador y Chile, en pleno proceso ${ }^{87}$ ).

En un esfuerzo por describir los distintos aspectos de esta crisis, analíticamente, Marissa Revilla propone la consideración de diversos factores, políticos, institucionales y sociales, que constituyen algunas de las condiciones que median entre las situaciones potenciales de conflictividad, las movilización colectiva y esta crisis del sistema de representación partidario ${ }^{88}$ :

- Desapego hacia la democracia como sistema político, como consecuencia del cuestionamiento de las instituciones representativas y el descrédito de los políticos (por ejemplo: el «Que se vayan todos» en Argentina).

- Rigidez institucional. Instituciones políticas como el presidencialismo añaden dificultades para la resolución de las crisis políticas y no se proveen mecanismos adecuados para la canalización de los conflictos.

- Destrucción de espacios de concertación social para la institucionalización del conflicto (destrucción de canales institucionales).

- Fortalecimiento de la capacidad autoorganizativa y las habilidades políticas. Mediante su acción colectiva popular los nuevos movimientos sociales logran aumentar los recursos disponibles para la movilización. La propia experiencia democrática redunda en el fortalecimiento de las culturas políticas participativas o de expresión política de demandas e incentiva el desarrollo de una cultura de derechos y de reivindicación de esos derechos.

- Al respecto, para Garretón con la «postransición democrática» se ha producido una transformación del panorama clásico de los partidos en

87. No evaluamos aquí la profundidad o legitimidad del proceso, solo constatamos el impacto y potencia alcanzada por la movilización estudiantil.

88. Revilla (2005) pp. 39-40. 
América Latina, en que han surgido nuevos partidos que expresan a sectores combatientes o sectores sociales marginados como grupos étnicos; colapsan sistemas de partidos; se fortalecen otros, mientras en todas partes se forman coaliciones entre partidos para alcanzar el gobierno y asegurar su estabilidad. De esta forma los partidos en América Latina perdieron sus proyectos lo que explica el deterioro coyuntural de su relación con la ciudadanía ${ }^{89}$.

\section{Nuevos movimientos y partidos políticos ${ }^{90}$}

En una mirada general a la relación entre partidos políticos y movimientos sociales, siguiendo a Fernanda Somuano, podemos plantear que los partidos políticos enfrentan una problemática en tres dimensiones: «desde arriba» por el debilitamiento del Estado como referente de la acción social; «desde el medio", por los propios problemas de reorganización del sistema de partidos; y «desde abajo», por los nuevos movimientos que disputan el papel de mediación a los partidos en la sociedad. En particular, los movimientos sociales «dan apoyo material y espacio organizacional a sectores pobres o débiles cuando éstos no pueden actuar en política de manera directa; contribuyen a enlazar estos sectores con las instituciones nacionales e internacionales», facilitando un espacio de participación más amplio que los partidos. Pero, advierte Somuano, los movimientos enfrentan sus propios problemas al entrar en el espacio de la mediación partidaria, porque al sustituir actorías políticas, corren el riesgo de promover intereses propios, particulares, o bien de radicalizar la acción social y política «reclamando una democracia directa que haga tambalear el entramando institucional». En contrapartida, también ocurre que los partidos políticos «tienden a desechar acciones que no lleven a ganancias políticas inmediatas» clientelizando su accionar en la interacción con las demandas sociales ${ }^{91}$.

89. GARretón (2004b) pp. 79-80.

90. Seguimos en esta parte a Fernanda Somuano (2007) pp. 40-50, que, a su vez, cita a Michael Hangan, "Social Movements. Incorporation, Disengagement and Opportunities. A Long View,» en Marco Giugni, Doug McAdam y Charles Tilly (eds.), From Contention to Democracy: Lanham, MA, Rowman and Littlefield Publishers, I 998.

9I. SOMUANO (2007) p. 52. 
En particular, como actores sociales, los movimientos sociales y los partidos políticos pueden presentar diversas interacciones. Al respecto, Somuano desde un enfoque que releva el rol mediador institucional de los partidos políticos, describe cinco tipos de relaciones: articulación, permeabilidad, alian$\mathrm{za}$, independencia y transformación ${ }^{92}$, las que revisaremos sucintamente, para detenernos en la relación de «transformación», por su gran impacto en los escenarios sociopolíticos actuales, con ejemplos como los del MAS en Bolivia.

Bajo la interacción de articulación los movimientos sociales se agrupan alrededor del programa de un partido político y promueven entre sus integrantes los fines partidistas en busca de apoyo. Aun cuando los partidos políticos mantienen el control, generalmente estos movimientos logran ejercer alguna influencia sobre el partido. En caso de éxito electoral -obtenido o reforzado al incorporar las «masas» del movimiento hacia la causa del partido-, se les asegura a los líderes «ciertos cotos de poder» en el partido y el apoyo institucional a la causa del movimiento, esperándose, recíprocamente, que los activistas del movimiento "sigan las líneas e instrucciones del partido ${ }^{93}$. En el caso que existe permeabilidad, el movimiento social infiltra al o los partido (s) para intentar orientar(los) hacia su causa. Esta estrategia requiere (y presume) que exista un apoyo considerable a la causa del movimiento dentro del partido político. Asimismo, debe existir un amplio rango de objetivos comunes con el partido político al que pretenden influir ${ }^{94}$. En una relación de alianza, los movimientos sociales negocian con partidos determinados o facciones de partidos, acordando la colaboración cercana en asuntos específicos, pero en las que tanto el partido como la organización retienen su propia estructura separada y libertad general de acción. Las coaliciones o alianzas implican que cada parte espera obtener beneficios específicos y concretos; éstas se disuelven si las expectativas no se cumplen. Un ejemplo de permeabilidad que pasa a alianza es el caso del triunfo electoral del Coronel Lucio Gutiérrez en Ecuador. El apoyo de la CONAIE como movimiento social, de Pachakutik como aparato electoral y del (Movimiento de Trabajadores desocupados (MTD), con Gutiérrez presentándose como el representante de un amplio espectro de fuerzas sociales opuestas a las políticas neoliberales, hicieron posible su triunfo electoral en 2002. Sin embargo, tan sólo seis meses después, las dirigencias de

\footnotetext{
92. Somuano (2007) p. 4I.

93. Somuano (2007) p. 4I.

94. Somuano (2007) p. 42.
} 
Pachakutik y la CONAIE se dieron cuenta de que habían sido utilizados y que Gutiérrez los había «traicionado». Pronto sería derrocado ${ }^{95}$.

Como vemos, tanto en el primer caso de una articulación (con un claro factor, a lo menos potencial, de coaptación prebendal), como en el segundo de la permeabilidad (que supone un alineamiento en los objetivos que no se puede asegurar) y en alguna medida el tercero de la alianza (que requiere equilibrios políticos y lealtades también imprevisibles), estas formas de relación o eventuales estrategias desde los movimientos hacia los partidos, se sostienen sobre la base de la subordinación de los movimientos a los entes partidarios, lo que limita sustancialmente su autonomía. En el sentido contrario, como hemos revisado, en general la acción colectiva movimiental avanza y profundiza procesos de autonomización, aunque los mismos ejemplos permiten advertir, no obstante, que siguen siendo repertorios disponibles.

Cuando existe una estrategia de independencia, el movimiento social actúa autónomamente de los partidos políticos, pero se relaciona con ellos presionándolos para obtener medidas en apoyo a la agenda del movimiento, las que de no implementarse podrían generar la pérdida seria de votos de parte de quienes apoyan el movimiento. Esta estrategia supone capacidad electoral significativa y autónoma en el movimiento o bien el que exista suficiente apoyo para el movimiento dentro del partido político al que se presiona, lo que, a su vez, pone al movimiento en una fuerte posición de negociación, pero genera un riesgo para la agenda más reformista del movimiento. Es el caso del Movimiento de los Trabajadores Rurales Sin Tierra (MST) y su vinculación con el Partido de los Trabajadores (PT) en Brasil. El MST —autodefinido como un movimiento de masas autónomo, al interior del movimiento sindical, sin vinculaciones político-partidarias o religiosas- y su coincidencia ideológica con Lula en favor de la Reforma Agraria, antes y después de ser presidente, le aseguró el apoyo electoral del MST en las cuatro ocasiones en que se presentó a elecciones presidenciales ${ }^{96}$.

Finalmente un movimiento social puede desarrollar un proceso de transformación. En este caso los movimientos sociales se convierten en partidos políticos. Las organizaciones que constituyen la base o el antecedente de los movimientos sociales pueden empezar articulando las diversas demandas de los movimientos sociales en acción. Luego, si crecen, pueden llegar a ser «partidos

95. Somuano (2007) pp. 43-44.

96. SOMUANO (2007) p. 46. 
gobernantes o en el poder» y lograr instalar sus demandas en la agenda de gobierno mediante «su propio poder electoral» y no solo como consecuencia de la incidencia y la movilización de repertorios propios de los movimientos. La decisión de un movimiento de trabajar con o en un partido político involucra una identificación importante con los otros objetivos del partido. Estas formas de relación generan importantes tenciones dentro de los movimientos sociales y de los partidos constituidos por ellos, debido a que los movimientos sociales se acomodan más como "partidos de protesta", pero obtienen más beneficios como «partidos en el poder», pero, con el tiempo, los miembros pueden llegar a estar dispuestos a sacrificar las prioridades del movimiento por las del partido. Por el contrario, la independencia de los movimientos y sus organizaciones centra la atención de sus miembros en las demandas específicas de éste, recalcando su importancia. Mientras, la independencia del movimiento se justifica mayormente cuando el eje del movimiento tiene amplio apoyo social y político $^{97}$. Procesos como el de «Revolución Democrática» en Chile muestran esta dinámica. Para nosotros, el MAS en Bolivia se presenta como un caso en que uno o varios movimientos sociales se «transformaron» en partido político. En estos casos, la participación por la vía institucional de los movimientos sociales tiende a que el sistema intente cooptarlos y desmovilizarlos ${ }^{98}$. Por ello y como puede constatarse en la revisión histórica y actual de las interacciones políticas del MAS y las acciones de gobierno recientes con Evo Morales al comprometerse o pasar a formar parte del sistema político, mediante un partido político, aunque se le señale al MAS bajo un propósito «instrumental», ha representado el fin para el movimiento social, porque las limitaciones institucionales lograr un cambio más radical a las que debió adecuarse como partido de gobierno, hicieron muy difícil de cumplir con la agenda del movimiento ${ }^{99}$.

En contrapartida, la interacción de los movimientos sociales con los otros actores sociales mediante nuevas formas de articulación de intereses y aspiraciones, que son también nuevas formas de mediación con el Estado, trazan un camino de aprendizaje para los partidos políticos, porque ellos deben asumir la responsabilidad y necesidad de renovarse si esperan mantener o recuperar su rol de mediadores de intereses diversos, al quedar en evidencia la capacidad de mediación de los nuevos movimientos sociales. En consecuencia, «la recu-

97. SOMUANO (2007) pp. 48-49.

98. Somuano (2007) pp. 48-50.

99. Somuano (2007) p. 50. 
peración de la confianza de los ciudadanos en las diversas instituciones democráticas (partidos, congreso, ejecutivo)» requiere nuevos espacios de control y participación ciudadana en la toma de decisiones de los asuntos públicos, para ello los movimientos sociales han abierto amplias alternativas para canalizar la participación social y sus demandas ${ }^{100}$.

\section{Debates sobre la «Matriz sociopolítica» en América Latina: ¿"Descuajeringamiento» o transformación «mercado-céntrica?}

Presentado un breve mapa de los escenarios sociopolíticos en América Latina en el siglo XXI, a continuación abordamos un debate en torno a la configuración o más bien la transformación de lo que se ha denominado la «Matriz Sociopolítica» en América Latina, considerando principalmente, dos propuestas teóricas. Por una parte, la «Matriz Sociopolítica», "Clásica» o del «Estado Nacional Popular», que Manuel Antonio Garretón estructura sobre la base del «Estado, el sistema de representación política (los partidos políticos o el sistema de partidos políticos) y la base material socio cultural». Desde ya, este autor advierte que esta matriz, que podemos considerar "Estado-céntrica», se encuentra en crisis o más bien desarticulada («descuajeringada» -en sus palabras-) frente al nuevo Estado "postindustrial globalizado», que no habría dado paso a una nueva matriz sociopolítica, pero sí interpela a una redefinición, rearticulación y reposicionamiento de los partidos políticos como «único» mecanismo efectivo de intermediación entre la sociedad civil y el Estado. En Segundo lugar, la propuesta de una matriz que se define por Juan Carlos Gómez como «mercadocéntrica», configurada desde tres ejes: «Estado, el mercado y la Sociedad Civil».

Matriz sociopolítica latinoamericana ${ }^{101}$

Para Garretón en toda sociedad humana, en que el poder político no se iden-

IOO. SOMUANo (2007) p. 53.

ior. Véase, Garretón (2000; 200I; 2002) quien, a su vez, recoge la denominación de «matriz nacional popular» y «matriz Estado-céntrica», respectivamente, de Touraine (I989); Germani, G., "Política y sociedad en una época de transición. De la sociedad tradicional a la sociedad de masas", Buenos Aires, Edit. Paidos (I965); y Cavarozzi, M., "El capitalismo político tardío y su crisis en América Latina, Homo Sapiens Ediciones, Argentina (1996). 
tifica con el cuerpo social, puede estructurarse la vida política mediante una Matriz Sociopolítica ${ }^{102}$ —que llamamos «Estado-céntrica»— articuladora de la relación Estado, régimen político y base social:

El Estado, cristaliza las relaciones de poder y dominación. Es la autoridad política o el poder político legitimado, pero, al mismo tiempo, es momento de la unidad simbólica y de dirección general de la sociedad (Estado-nación);

El régimen político o sistema de representación (instituciones, sistema de partidos $)^{103}$. Corresponde a la mediación institucional, regida por normas y organizaciones, entre la base social y el Estado. Garretón lo define como «la relación institucional entre Estado y sociedad orientada a resolver institucionalmente las cuestiones de gobierno, la vinculación de los individuos con el Estado y la resolución de conflictos con demandas sociales» ${ }^{104}$. Agrega que en toda colectividad el régimen político persigue resolver, a su vez, tres problemas fundamentales:

- El del gobierno, es decir, quién y cómo se gobierna;

- El de la ciudadanía y su representación ante el Estado. Esto es, las relaciones entre las personas y el Estado;

- La institucionalización de las demandas sociales y formas de resolución de los conflictos.

La base social. Está constituida por la gente, la sociedad civil, y los actores políticos. Se trata de la base cultural y socioeconómica de los actores sociales (sociedad civil y economía) ${ }^{105}$.

En relación al sistema de representación y los partidos políticos - dice Garretón- «si lo fundamental de la democracia en cuanto forma de gobierno es la representación de la voluntad ciudadana y la conducción de la sociedad por representantes de esa voluntad, hasta hoy no se conoce un mejor sistema de representación que los partidos, más allá de cualquier crítica que pueda hacérsele a su funcionamiento en las diferentes sociedades». Argumenta que ni la participación directa en la esfera pública, ni los medios masivos, las campañas comunicacionales o las redes sociales pueden reemplazar el momento partidario

IO2. GARRETÓN (2004b) p. 74.

IO3. MiRZA (2006) p. 52.

IO4. GARRETÓN (2004a) p. 226.

I05. MiRZA (2006) p. 52. 
de una democracia» ${ }^{106}$. Así, en relación a los tres problemas indicados que busca resolver todo régimen político (gobierno, ciudadanía e institucionalización de las demandas sociales), que se traducen en el modo cómo la democracia procesa estos problemas, para Garretón los partidos cumplen las siguientes funciones:

- Representación de intereses globales, ideas y proyectos;

- Convocatoria, liderazgo y conducción;

- Elaboración de proyectos o de propuestas; de administración de gobierno o de oposición;

- Agregación de demandas y de canalización de conflictos;

- Reclutamiento para los puestos del Estado o de la función pública.

Agrega al respecto que los partidos políticos no cumplen exclusivamente ninguna de estas funciones, pero son la única institución, en la sociedad denominada «moderna», que está llamada a cumplir con todas ellas. Así, los partidos políticos o, más bien, el «sistema de partidos» — como prefiere llamarlos ${ }^{107}$ - son «el principal vínculo de la política democrática con la sociedad, porque tratan a ésta en cuanto ciudadanía». Sin embargo -aclara- que la relación de los partidos políticos con la ciudadanía «es siempre mediada», porque no hay partidos de ciudadanos, sino que cada partido apela a un sujeto político específico definido por una categoría como proyecto, pueblo, clase o identidad. Entonces, la relevancia de los partidos políticos y del sistema de partidos en cada sociedad, su capacidad de articular ciudadanía y Estado mediante la participación política y la representación, dependerá de cómo se constituyeron y desplegaron los respectivos regímenes democráticos, según las dinámicas sociohistóricas en cada caso. Particularmente, variará si se trata de procesos de democratización, de las eventuales crisis o si la democracia ya es un régimen político consolidado. Pero, al mismo tiempo, los partidos «contribuyen a moldear» las características del respectivo régimen político democrático e inciden en los procesos de democratización ${ }^{108}$.

IO6. GARRETÓN (2004b) p. 76.

I07. Define el «Sistema de partidos» como «la configuración del espectro partidario completo en una determinada sociedad o momento histórico de ella, que, al tiempo que describe los partidos individuales, abarca el conjunto de las relaciones entre ellos, pudiendo coexistir al interior de un sistema diversos modelos de partidos individuales», Garretón (2004b) p. 78.

IO8. GARRETón (2004b) pp. 76-78. 
Finalmente, en esta matriz el partido define su propuesta política a partir de «los clivajes» o conflictos de cada sociedad, representando a grupos de esa comunidad socia, ideológicos o culturales, que comparten una misma visión, necesidades, intereses o aspiraciones ${ }^{109}$.

La desarticulación de la matriz sociopolítica «clásica» y la «sociedad post industrial globalizada» ${ }^{110}$ :

Como hemos anunciado y según describe Garretón, la matriz «nacional popular» se desarticuló tras las diversas transformaciones económicas, políticas y emergencias sociales de las últimas 4 décadas, lo que arrojó un impacto en los sistemas de partidos porque se tendió a perder la centralidad de la política como expresión exclusiva de la acción colectiva. Luego, con un Estado debilitado en su papel de agente de desarrollo y distribuidor de recursos, también, como referente en el plano simbólico (pero que sigue siendo fuerte en el plano regulador), quienes representaban intereses ante el Estado o que mediaban las relaciones sociales y políticas (los sistemas de partidos o los partidos mismos), fueron perdiendo poder y relevancia como interlocutores de las demandas sociales. Se demandó a los partidos soluciones que ni el mercado y sus fuerzas, ni los medios de comunicación o la racionalidad de intereses, lograban articular $^{111}$. En este sentido, si bien el capitalismo globalizado y la democracia política «eran los únicos proyectos no sólo deseables sino posibles», el mundo de la tecnocracia económica y de los publicistas y expertos comunicacionales pasó a dominar las elites partidarias. De modo que podría decirse que el principal déficit de los partidos fue "su incapacidad de formulación ideológica y de proyectos» en este nuevo escenario político-económico ${ }^{112}$. Mientras, en contrapartida, quienes representaban intereses, principalmente corporativos, se enfrentaron directamente con el mercado o se trasformaron en "poderes fácticos» de éste. Luego, los actores clásicos, como clases y movimientos en torno a la producción y la distribución centrados en torno a la política estatal, tendieron, tanto a corporativizarse básicamente en términos de organizaciones gremiales, como a segmentarse, lo que ocurrió con los sectores laborales más marginales. Por su parte —continúa Garretón- los actores nuevos ligados principalmente a temas culturales o a cuestiones de medio ambiente, dere-

IO9. GARRETÓN (2004b) pp. 83-84.

i io. Véase: GARRETón (200I; 2004b).

I I I. GARRETÓN (2004b) pp. 82-83.

I I2. GARRETón (2004b) p. 90 
chos humanos, género y defensa de identidades, lograron levantar demandas y ponerlas en la agenda pública y, incluso en el discurso social, pero -recalca el autor- "muy difícilmente aseguran establemente su representación política en partidos propios». Propone Garretón como ejemplos de esta capacidad de incidencia, pero con falta de representación en partidos, a los movimientos ecologistas y de mujeres, aunque considera una posible excepción a los partidos que asumen la representación de los pueblos indígenas ${ }^{113}$.

En este marco, la hipótesis central de Garretón sostiene que la descomposición de la matriz sociopolítica influyó decisivamente en la modificación de la naturaleza del movimiento social y también en la resignificación de los nuevos ejes de la acción social colectiva y los conflictos sociales ${ }^{114}$. Desde esta perspectiva, entonces, hoy resulta difícil encontrar un movimiento social central ${ }^{115}$. Al mismo tiempo, pese al debilitamiento del sistema de partidos políticos aunque nos resulte paradójico- para el autor los partidos seguirían siendo los únicos con la capacidad de mediar e institucionalizar las demandas sociales ante el Estado. En consecuencia, interpela a la redefinición de los partidos y los sistemas de representación, como la vía dentro de la democracia representativa y como alternativa al mercado, para la reconstitución del espacio institucional en que la política vuelve a ser el centro articulador de actores sociales hoy

I I3. GARRETón (2004b) p. 86. En sentido estricto la existencia de partidos políticos indígenas también es excepcional, porque en su gran mayoría los casos corresponden a articulaciones de organizaciones indígenas, que alcanzan capacidad de incidencia política, como la CONAIE en Ecuador y la CONAMAC en Bolivia. Incluso, parece ser el caso del Partido Político Indígena Yatama de Nicaragua, emblemático por haber obtenido un fallo a favor de la Corte Interamericana de Derechos Humanos en 2005, ya que si bien con la sentencia conquistó su reconocimiento oficial, siempre se planteó como medio de representación de las diversas comunidades indígenas del país, defendiendo las formas tradicionales ancestrales de organización y toma de decisiones propias. En el caso Chileno, excepcionalmente destaca Wallmapuwen (Partido Político Autonomista Mapuche), que se ha planteó derechamente el objetivo de integrarse al sistema de partidos políticos. Sin embargo, por más de una década el propio sistema legal de partidos lo marginó por incumplimiento de diversos requisitos formales. Solo bajo la reciente normativa (Ley 20.840 del 5 de mayo de 2015 ) que dio fin al sistema binominal chileno imperante por más de 25 años, Wallmapuwen logró su inscripción oficial como partido político regional el 2 de junio de 20 I 6.

I 4. MirZa (2006) p. 53.

I I 5. GARRETÓN (200I) p. 34. 
autónomos y fuertes, con «un Estado que recobra su papel de agente de desarrollo en un mundo que amenaza con destruir las comunidades nacionales» ${ }^{116}$.

Así, afirma Garretón que la transformación de la política se expresa «en una tensión entre las tendencias fácticas que la llevan a su banalización y disolución y las propuestas normativas que apuntan a la resignificación de su centralidad en las nuevas circunstancias». Se trata de un contexto en que «los conflictos no son superposiciones de ejes en que todos están en el mismo polo, sino expresión multidimensional de fraccionamientos, en que la resolución de uno no puede trasladarse a otro». Metafóricamente, podríamos decir nosotros, que la política, los sistemas de partidos, sujeta(n) múltiples hebras entrelazadas y tensionadas, un «nudo de nudos» que envuelve a los partidos. Bajo esta visión, son tensiones -todas, «multidimensionales y fragmentadas»- que deben ser canalizadas por los partidos políticos (ellos deben «desatar» este gran nudo) en su rol de mediación entre la sociedad y el Estado como único camino que tendría la democracia representativa ${ }^{117}$. Por cierto, para nosotros, tal desafío puede resultar imposible en el nuevo escenario regional.

\section{¿Se ha configurado una nueva matriz sociopolítica en América Latina?}

En el complejo contexto descrito de diversos clivajes y reconfiguraciones del conflicto social en América Latina, para Garretón, así como está clara la desarticulación de la matriz "clásica», no es posible afirmar que exista una reconfiguración definitiva de las fuerzas sociales, del sistema de representación y del Estado como para encontrarnos en presencia de nueva matriz socio-política que articule «el fortalecimiento, autonomía y complementariedad entre el Estado, el régimen [político], los partidos y los actores sociales autónomos» ${ }^{118}$. En consecuencia, aparecen nuevas problemáticas que no logran expresarse por los partidos políticos, como los temas ambientales, de género o problemas étnicos que «atraviesan transversalmente los partidos constituidos». Agrega que no se sabe precisamente cuál es el conflicto o los intereses en tensión, lo que genera que muchos de los fraccionamientos propios de la sociedad posindustrial globalizada sean leídos como conflictos, sin que aún originen posiciones definidas en torno a las cuales constituir adversarios y proyectos políticos o propuestas

I I6. GARRETÓN (2004b) pp. 82-83.

I 77. GARRETÓN (2004b) pp. 82-85.

I I 8. GARRETón (2004b) p. 95. 
"que permitan delinear un continuo partidario o un continuo de representación respecto de las soluciones que se proponen para este problema» ${ }^{119}$. No obstante ello, aunque aún es difícil sostener que se construyó un nuevo modelo de desarrollo, tras la desarticulación del previo $^{120}$, si sería posible proponer la existencia de una problemática relativamente reciente que pude ser configurativa de una nueva matriz socio-política latinoamericana, aunque aún no ha cristalizado $^{121}$. Para Garretón se trataría de lo que la CEPAL ha denominado «la cuestión de la cohesión social» o «la igualdad», como demanda que supone «reconstruir las relaciones entre Estado y sociedad» ${ }^{122}$.

Esta nueva problemática central en configuración tiene o tendría, a lo menos, tres «niveles de realización» (local, nacional-estatal y supra-nacional). Al mismo tiempo, en cuanto contenido, supone tres grandes dimensiones: primero, un «núcleo ético» o "consenso ético» fundante, previo o al margen de mayorías electorales consistente en la «cohesión moral de la sociedad» u «horizonte de sentido», el proyecto de país. En este núcleo o moral social latinoamericano, a lo menos, se podría reconocer un consenso en torno a las cuestiones de derechos humanos, la valoración de los pueblos indígenas, de la democracia, junto a la búsqueda de la solidaridad y la igualdad. En segundo lugar, se integran «las bases estructurales e institucionales de una comunidad socioeconómica», que sintetiza en la cuestión de la «igualdad»o «justicia social», esto es, «las distancias mínimas y razonables, y nunca fijadas, entre los miembros de una sociedad» que suponen la redistribución de «poder y riqueza». En consecuencia, implica también la redefinición de un «modelo productivo" y una "fórmula redistributiva» en que el Estado, legitimado, juega un rol fundamental de redistribución. Adicionalmente, se suma a este punto la cuestión de «los derechos ciudadanos», actualmente no garantizados por el Estado (a lo menos todos), porque, desplazado el Estado, se proveen por el sector privado, lo que exige repensar los mecanismos de aseguramiento futuros en el

I I9. GARRETÓN (2004b) p. 85.

I 20. GARRETÓN (20IO) p. 2 I 5 .

I2I. GARRETÓN (20I2) p. 57.

I22. En este sentido, Luis TAPIA (2007; 20II) sostiene que la democracia debe entenderse sostenida en el principio de igualdad, pero no como máxima formal, sino entendida como igualdad social y política, basada en la justicia social y el co-gobierno o derecho a ser parte de las propias decisiones políticas. 
sentido de su nacionalización o al menos su aseguramiento por el Estado ${ }^{123}$. Finalmente, para Garretón, un tercer elemento es una «forma de organización política democrática decidida por la ciudadanía». Al respecto, el mismo autor se adelanta a decir que, más allá de algunos avances en experiencias de democracia participativa, se está aún lejos de "cristalizar fórmulas institucionales» que aseguren una efectiva presencia en la toma de decisiones sin lesionar los principios de representación y pluralismo ${ }^{124}$.

\section{Matriz latinoamericana «mercado-céntrica»}

Bajo el mismo escenario que hemos descrito y analizado desde Garretón, para Juan Carlos Gómez, el estudio de la situación política actual de América Latina requiere considerar el surgimiento y desarrollo de nuevos conflictos sociopolíticos, históricos económicos e ideológicos que emergen a partir de, por una parte, la restructuración capitalista neoliberal y, por otra, la instalación de las democracias neoliberales. De esta forma, el nuevo conflicto social, político y económico confronta a actores que se mueven en una matriz de tres campos, espacios o formaciones socioeconómicas neoliberales: «el Estado, el mercado y la sociedad civil». Se trata de una reconfiguración económica, social y política, a diferencia del "conflicto a dos bandas que se desarrolló en las sociedades capitalistas industriales sustitutivas» de la matriz «nacional-popular» que operaba entre actores instalados en el Estado y otros ubicados desde la sociedad civil. En la anterior «el Estado controlaba y dirigía al mercado y a la sociedad civil a través de múltiples mecanismos políticos e institucionales» ${ }^{125}$. Pero bajo la nueva matriz, la restructuración capitalista neoliberal modificó radicalmente la configuración «Estado-céntrica» precedente, para instaurar una matriz «mercado-céntrica». Bajo esta nueva matriz el mercado «define y condiciona las relaciones con el Estado y con la sociedad civil, en tanto ha logrado obtener autonomía relativa del Estado mismo, de los poderes políticos e incluso ha entrado en confrontación con ellos, particularmente cuando los gobiernos han intentado regular al mercado o sus «mercaderes». Ahora bien, en esta matriz el Estado no ha dejado de ser relevante, si bien ha cedido diversas funciones sociales, políticamente, sigue siendo poderoso desde sus funciones de control,

\footnotetext{
I23. GARRETón (20I2) pp. 63-64.

I 24. GARRETÓN (20IO) pp. 2 I 7-220.

I 25. GÓMEZ (20I2) pp. I70-I72.
} 
supervisión y vigilancia. Por otra parte, este Estado neoliberal entró en conflicto con la sociedad civil, empoderada precisamente por la acción de abandono de las funciones sociales y económicas, junto a la crisis del rol mediador del sistema de partidos. Bajo este proceso, la sociedad civil de las últimas tres décadas debió buscar otras formas de organización social y de acciones colectivas para hacer frente a la restructuración neoliberal, dando lugar a una red de (nuevos) movimientos sociales, empoderados desde una sociedad civil que se ha confrontado tanto con el Estado, como con el mercado neoliberal, lo que configuró el nuevo tipo de conflicto político en América Latina ${ }^{126}$. En este sentido, son claros los ejemplos de la movilización por «educación pública, gratuita y de calidad» del movimiento estudiantil chileno o el del movimiento indígena en América Latina, en general. En el primer caso, más allá de un éxito difícil de pronosticar, la demanda social ha cuestionado el propio modelo económico y educativo que mercantilizó la educación (instalado por el Gobierno Militar y asegurado constitucionalmente en I980, luego consolidado por los propios gobiernos democráticos posteriores), exigiendo al Estado (a sus respectivos gobiernos de la última década) la transformación del sistema educacional en sus diferentes niveles. Por su parte, un aspecto central y común de las demandas indígenas de la región es su resistencia a los proyectos de inversión extractivista en sus territorios ancestrales, en tanto ponen en riego su propia supervivencia (social, ambiental y cultural), con lo que sus resistencias se ubican en el centro del modelo neoliberal basado en la mercantilización y explotación de los recursos naturales.

\section{Estado y mercado, los nuevos ejes del conflicto}

A continuación proponemos algunas reflexiones frente a las proposiciones revisadas de la llamada crisis de la matriz «Estado-céntrica» y, en particular, el rol de la acción colectiva y mercado en esta transformación que habría dado lugar a una nueva matriz «mercado-céntrica».

Cuando Juan Carlos Gómez ubica al mercado en el centro de la nueva matriz del conflicto social en América Latina, lo expone como un «nuevo conflicto social, político y económico» ${ }^{127}$, asumiendo desde ya lo que podríamos llamar «la derrota subalterna» refrendada con el caso de Chile, ante el triunfo

I 26. GÓMEZ (20I I) pp. 59-6I.

I 27. GÓMEZ (20I I) p. 59. 
del proyecto neoliberal hegemónico ${ }^{128}$. Ahora bien, tanto desde la perspectiva de la crisis de la matriz clásica aún no reconstituida, planteada por Garretón, como desde la profundización neoliberal que indica Gómez, vemos dos caminos para un diagnóstico común de transformaciones profundas y neoliberalización en las sociedades latinoamericanas. Nuestras sociedades fueron marcadas por los ajustes estructurales y las reconstituciones democráticas de las décadas pasadas, la pérdida de gravitancia de los movimientos sociales centrales (como el obrero). Paralelamente los partidos políticos entran en crisis en su rol de intermediación entre la sociedad civil y el Estado, y constatamos la emergencia de nuevas identidades y los denominados «nuevos movimientos sociales». La diferencia principal entre una y otra matriz, radica en el rol que se atribuye al mercado y a los partidos políticos en el escenario actual.

Así, en la lectura «mercado-céntrica» el mercado se consolida como mecanismo que condiciona e intermedia las relaciones sociales ante la crisis de los partidos políticos. En este marco, las recurrentes crisis financieras de orden global (en particular la de 2008), lejos de la «derrota» del mercado, solo reflejan la inestabilidad cíclica de las economías, como una característica propia del mercado, que, no obstante todo, se sigue afianzando en las sociedades latinoamericanas. En este sentido, Gómez describe el giro de una a otra matriz, señalando que en las sociedades industriales sustitutivas de importaciones en la que se desarrollaba la matriz «estado-céntrica», "el estado controlaba y dirigía el mercado y a la sociedad civil a través de múltiples mecanismos políticos e institucionales», pero la restructuración capitalista neoliberal modificó radicalmente el escenario bajo la matriz «mercado-céntrica», en la que ahora el mercado «define y condiciona las relaciones con el Estado y con la sociedad civil». Emancipado del Estado, el mercado «ha logrado obtener una autonomía relativa de los poderes políticos y, en muchas ocasiones, ha entrado en confrontación directa con ellos» ${ }^{129}$.

De esta forma, observamos cómo, sin perjuicio del factor corrupción (que bien puede ser parte del mismo fenómeno) y las cuestiones de liderazgo, el recientes fracaso «kirchnerista», más las presentes crisis «chavista» y del PPT brasileño, corroboran el conflicto «mercado-Estado, mostrando una estrepitosa caída de las propuestas «desarrollistas» que procuraron una intervención más frontal del mercado desde el Estado. En el mismo sentido, los proyectos

I28. GÓMEZ (2010).

I29. Gómez (20I I) pp. 59-60. 
de corte más «progresista», como los de Bolivia y Ecuador, tras sus respectivos procesos constituyentes de la primera década del siglo XXI, se vieron obligados a "girar», o a lo menos «moderar», sus procesos de reapropiación estatal frente a los requerimientos del mercado globalizado. Con estos «sacrificios» han logrado sortear su gobernabilidad, pero a un precio que bien puede llegar a ser el propio proyecto «revolucionario». Por ejemplo, el año 20 I I el gobierno de Evo Morales en Bolivia, impelido por las presiones externas, dispuso un alza general de precios de los combustibles. Solo tras el llamado «Gazolinazo», en que la ciudadanía del país se levantó en una protesta general, revertió la medida, pero esta «concesión» fallida a las transnacionales bien pudo costarle el gobierno.

Con todo, consideremos o no la eventual consolidación de la matriz «mercado-céntrica», o bien, la cristalización de un nuevo conflicto central en torno a la demanda por igualdad en un sentido social y político, es un hecho que la matriz «nacional popular» —usando las palabras de Garretón- se «descuajeringó» y el desarme se produjo, precisamente, en el sistema de representación partidario, por más central y relevante que pueda o deba ser su rol para las democracias representativas de América Latina. De esta forma, aunque «los partidos siguen representando a la clase política», no logran representar a la sociedad, pero sí sus propios intereses, que no necesariamente se identifican con un proyecto colectivo de bien común. Mientras, el control del poder en sí y del Estado en particular, lo han ido perdiendo los partidos políticos en favor de los «poderes fácticos» económicos y transnacionales ${ }^{130}$.

En el escenario descrito Garretón interpela, —como esfuerzo «voluntarista» o «principio ético-político básico»— a «la reconstrucción de una comunidad política» en la que «los partidos redefinan el sentido de la política, de acuerdo a las nuevas condiciones sociales, políticas, económicas y culturales», con los partidos como forma y momento insustituible de la representación de la sociedad ${ }^{131}$, pero integrando la representación de los sectores populares diversificados, bajo «la profundización de las instituciones democráticas y la expansión de los sujetos individuales y colectivos» ${ }^{132}$. Al respecto, consideramos que, más allá de una actoría social determinada, de los partidos o los movimientos, unos y otros necesitan de la democracia y sus acciones e interac-

\footnotetext{
I3O. GARRETÓN (2004b) p. 9 I.

I3 I. GARRETÓN (2004b) p. 93.

I32. GARRETón (20I2) p. 67.
} 
ciones inciden en su debilitamiento o profundización, teniendo al alcance distintas dimensiones de resistencia contrahegemónica, contra el mercado como antagonista común. Pero no sabemos si el Estado, los partidos y la sociedad con sus movimientos serán capaces, a la vez, de autonomizarse del mercado, fortalecerse y complementarse entre sí, porque «más que el autoritarismo y la presencia de otros regímenes no democráticos, el gran riesgo es la irrelevancia de las democracias frente a los poderes fácticos y la descomposición de las instituciones estatales y las estructuras de acción colectiva ${ }^{133}$. Si el sentido de la política en democracia adquiere un giro renovador en la reconstrucción de la institucionalidad y en la redefinición de la propia política, como articuladora entre actores sociales autónomos y fuertes con un Estado que recupera su papel como agente de desarrollo, ignoramos si las democracias representativas latinoamericanas serán capaces de tan magna tarea y, en ese sentido, seguimos en un escenario incierto ${ }^{134}$.

Así, Garretón -insistiendo en el esfuerzo "voluntarista ético-político», como el mismo lo llamó- advierte que si los partidos no ocupan el espacio de mediación entre el Estado y la sociedad civil «lo harán los mercados, la tecnocracia ilustrada, el poder del dinero o del mundo mediático, o el individualismo autoritario». Pese a todo, -para él- «en la opción forzada entre partidocracia, mercado, tecnocracia, movimientismo o fundamentalismo, no cabe perderse al apostar por los partidos» ${ }^{135}$.

Con estas últimas palabras nos queda clara la que podría ser una diferencia clave entre Garretón y Gómez. El primero aún no da por «vencedor» al mercado, es más, considera que los partidos políticos (representando ampliamente a los diversos sectores y junto a los movimientos) son los que debieran ocupar el espacio de mediación intersocial y socioestatal, pero al mismo tiempo constata la crisis e imposibilidades de los partidos políticos a quienes encomienda «titánica» tarea. Mientras Gómez, consiente de la crisis de los partidos en el nuevo escenario, sin pregonar futuros partidarios -ni buenos, ni malos o necesarios-, constata la «capitulación» de los partidos y la sociedad misma ante el mercado «triunfante», incluso en aquellas sociedades latinoamericanas donde el neoliberalismo ha recibido las mayores embestidas, como Bolivia.

Sin desconocer los pasos avasalladores del mercado que lo llevaron a ins-

I33. GARRETón (2004b) pp. 93-94.

I34. Mirza (2006) p. 54.

I35. GARRETón (2004) p. 95. 
talarse bajo la nueva matriz «mercado-céntrica», nos parece importante destacar que en el nuevo panorama de la acción colectiva, como hemos descrito, muchas cuestiones son retraídas, reapropiadas respecto del mercado o están en tensión con él, en «resistencia», dado lo cual, debe tomarse la precaución de no leer el posicionamiento del mercado como una «derrota» de la sociedad civil pero si como una rearticulación de la acción colectiva, de sus formas de representación y movilización.

Finalmente, entendida la sociedad civil, no como un actor central ni como un bloque, sino que rica en la heterogeneidad de los movimientos, se empodera y disputa espacios al Estado y al mercado. Podríamos decir que, ante la crisis de los partidos, disputa «mediaciones» o deja atrás las mediaciones representativas clásicas, para asumir la interlocución directa o la confrontación con el Estado. Pero, mientras ante el Estado la disputa se presenta franca y visible, por lo mismo los repertorios para la acción también emergen con claridad. Con el mercado, las tensiones suelen ser «grises» y se asientan, tanto, en las «reservas» de la «autonomía material» de los nuevos movimientos sociales, como, incluso, desde espacios que logran en el propio mercado.

\section{Bolivia, Estado y mercado en tensión ${ }^{136}$}

En una brevísima reseña que busca más bien engarzar el caso boliviano con las matrices propuestas, podemos plantear como hipótesis de trabajo que en Bolivia a lo largo de las movilizaciones sociales y dinámicas político-institucionales de los últimos I 5 años, Evo Morales junto al MAS, han implementado una estrategia para alcanzar el poder, gobernar y transformar la sociedad boliviana (revolucionariamente o no, lo que es materia de discusión), con mucha mayor inclusión, redistribución y participación de los sectores subalternos, previamente excluidos, pero sin transformar el patrón de acumulación capitalista extractivo exportador ${ }^{137}$.

I36. Sintetizamos algunas de las conclusiones desarrolladas en profundidad en Faundes (20i6). Véase también: Somuano (2007) pp. 49-50; García Linera (2004; 2006); Stefanoni (2006) pp. 38-40; Orellana (2006) p. 47; Prada (20i2); Kats (20I2) pp. II 8-I 20.

I37. Como dice Juan Carlos Gómez Leyton, propuestas como la boliviana de un «socialismo del siglo XXI... presentan demasiadas contradicciones como para sostener que van avanzando hacia la superación primero, del neoliberalismo, y, segundo, 
La complejidad del proceso sociopolítico boliviano ${ }^{138}$, por cierto que se palpa en los entramados del actual gobierno de Evo Morales y su tránsito desde la movimientalidad, el $\mathrm{MAS}^{139}$ y el sector cocalero, en alianza con la heterogeneidad de organizaciones indígenas, hasta su búsqueda de equilibrios y pactos, expresos o implícitos con la oligarquía derrotada electoralmente en 2005 , pero que sigue controlando en forma importante diversos procesos de acumulación, producción y exportación de su base económica. El éxito de sus políticas redistributivas le permiten mantenerse en el gobierno durante tres gobiernos consecutivos, pero sus dinámicas voluntaristas hacen crisis con el rechazo a un cuarto período consecutivo de gobierno en 2015.

En definitiva la propuesta "Evista», no obstante la mayor apertura democrática y las exitosas políticas redistributivas, no modificó del patrón de acumulación estructural extractivista boliviano, heredado del Estado nacional oligárquico, el que fue derechamente fue asumido por los nuevos gobernantes. Por su parte, los movimientos sociales impulsaron la transformación del Estado en alguna medida que se movían inconscientes en «los márgenes de la modernidad capitalista» lo que se recogió en la nueva democracia del Estado Plurinacional y su «Capitalismo andino amazónico» ${ }^{140}$ como propuesta de modelo desarrollo. Este modelo, plasmado constitucionalmente, se caracteriza por un «neodesarrollismo", con un Estado fuerte, pero no menos capitalista. Así, los movimientos sociales y sus acciones (la asonada a la Paz en 2003, el «Gasolinazo» el 20 I y el caso del TIPNIS en, entre otros), son el barómetro de una sociedad dividida y de un gobierno que debe sortear los clivajes de un

del capitalismo» (2010) p. 64. Así, podemos afirmar con Kats que «el logro de los objetivos que se ha propuesto el gobierno del Estado Plurinacional, a lo menos en el discurso de respeto del medio ambiente, de potenciar el cooperativismo, armonizado con procesos de consulta democráticas a los diferentes grupos con intereses y derechos en tensión, requiere «abandonar la estrategia del <<capitalismo andino amazónico>>», KATS (2OI2) pp. II 8-I 20.

I38. En este sentido, señala Albó que «hay varias versiones entrecruzadas de esas dos Bolivias polarizadas: blanca/mestiza vs indígena/originaria; urbana vs global; rica vs pobre; "colla» o andina vs «camba» u oriental;... la Bolivia globalizada vs la Bolivia profunda», Albó (2004) p. I 50.

I39. MAS (Movimiento al Socialismo), es el movimiento político que llevó a Evo al poder y lo ha acompañado en el poder como partido político.

I 40. GARCía (2004) p. 432. 
proyecto político institucional cruzado por un modelo de desarrollo que tensiona y hasta contradice en forma permanente la institucionalidad misma ${ }^{141}$.

Entonces, la crisis estructural radicada en el patrón de acumulación de base extractivista persistente, pese a la transformación constituyente-institucional, aunque muestra un desplazamiento relativo del control del capital hacia el Estado, sigue estando en el centro del conflicto social boliviano. Incluso el campo político boliviano ha tendido a profundizar sus fracturas como consecuencia de un nuevo sistema de partidos menos «mediado", mucho más directo, sostenido en la inclusión de los movimientos sociales en la toma de decisiones (más allá de la mayor o menor transformación «movimientopartidaria» del MAS), pero que no ha logrado dar respuestas suficientes para el conflicto social ${ }^{142}$.

Visto el caso del estado Plurinacional de Bolivia desde la matriz «mercadocéntrica», pareciera que los tres ejes de esta matriz se funden solo en dos: la sociedad civil que acorta las mediaciones participando con mayor intensidad de la toma de decisiones políticas, canalizadas en medida importante por el MAS, alineado con un Estado, «mercantilizado» o «capitalizado» (con el mayor control de empresas y la renegociación de contratos de explotación de hidrocarburos), aparentemente más poderoso, pero, en el fondo limitado por el patrón de acumulación extractivista y las formas económicas (las leyes de los equilibrios neoliberales), que el Estado boliviano asume, perpetuando su crisis y clivajes. Estas tensiones son un llamado de atención para los movimientos sociales en América Latina que también pueden verse atrapados en la paradoja desarrollista y la hegemonía del Mercado.

\section{Conclusiones}

En relación a la «emergencia» de una nueva problemática central dada por la demanda por igualdad social y política (la «cuestión de la cohesión social»), como propuesta de democratización social que pone en discusión Garretón, nos parece preliminarmente necesario distinguir dos posibles planos para la propuesta que respectivamente pueden tener alcances muy distintos. En primer término, considerarla como la eventual configuración de una nueva forma «matriz» del conflicto social. Y, por otro, su lectura como una "problemática»

I4I. PRADA (2OI2).

I42. ZEGADA (2OI3); ZEgADA, et al. (2OI I). 
o demanda compartida por las diversas expresiones de la acción colectiva en América Latina.

En nuestra opinión, Garretón, a partir de la identificación de lo que parece ser una nueva problemática central en «cristalización» propone un nuevo modelo democrático latinoamericano, que pudiese ser desplegado en uno o más estados, pero no podemos decir que tenga el carácter de matriz, en tanto esté, efectivamente, configurado o configurándose como un patrón general de conflicto para la región latinoamericana. Tampoco parece constituirse parcialmente o con diferencias locales, salvo quizás en el caso de Bolivia post constituyente, en desarrollo y con futuro incierto. Pero sí, desde la segunda perspectiva, estamos de acuerdo en que se puede identificar como una "problemática» relevante, que puede llegar a aglutinar a diversos movimientos sociales, como proyecto $\mathrm{u}$ horizonte, pero no nos parece que pueda haberse ya configurado o estarse configurando como la nueva matriz del conflicto social latinoamericano, porque la concreción de dicha matriz - para nosotros- supone, a lo menos, dos cuestiones relevantes, según sintetizamos a continuación.

Por una parte, implica que sus elementos y conflictos sean reconocidos, constatables, en los países, en sus sociedades, en sus respectivos marcos institucionales, en relación con sus regímenes políticos y, por cierto, en su respectiva base material socio cultural. $\mathrm{O}$, por lo menos, que tal constatación sea posible en un número significativo de ellos, de tal forma que en sus relaciones sociopolíticas pudiesen apreciarse los elementos principales de esta matriz, para lograr sostenerla como un tipo ideal aplicable al conjunto, aunque no se diese en todos y/o plenamente para todos los casos. Hablamos de un despliegue material del conflicto "social-democrático», visible y extendido en el contexto latinoamericano, en alguna medida desestabilizando y poniendo en crisis a la región, lo que está aún en un primario desarrollo. La «emergencia» de los movimientos sociales reclamando la democratización, radical-participativa y que releva las problemáticas sociales y la cuestión de la justicia social, aunque sea cada vez más significativa y en algunos casos haya generado cambios institucionales, como en Bolivia, no ha alcanzado a configurar una fuerza central reconocible en la globalidad de la región.

Por otro lado, hay un segundo supuesto que nos parece sustantivo, dado por una demanda con la potencia de aglutinar a los movimientos sociales. Como decíamos, si bien la mayor o menor extensión o retracción de los movimientos sociales debe revisarse, también hemos dado cuenta de la enorme heterogeneidad de proyectos y de la importancia que tiene la «autonomía» como 
condición de los nuevos movimientos, más otras características que, precisamente, dificultan la definición de un conflicto único o central. Sin embargo, también es muy cierto que "democracia participativa» o profundización democrática, «desde abajo»y «justicia social», son aspectos consustanciales a las demandas de los nuevos movimientos sociales en América Latina. El problema radica en que es difícil pensar, no solo en una actoría central, sino en un proyecto central que aglutine la diversidad de expresiones de la acción colectiva movilizada, aunque puedan tener aspiraciones u horizontes compartidos. La heterogeneidad será condición de existencia de los nuevos movimientos, fuente de fortaleza, pero también una debilidad.

Entonces, aunque diésemos por instalada la cuestión de la «democracia participativa» y la «justicia social» como un conflicto social central, hoy por hoy, su disputa principal sería tanto más con el mercado que con el Estado.

Desde la perspectiva de la acción colectiva, en la medida que existan sociedades latinoamericanas en plenos procesos de transformación, todas, de una u otra manera tensionadas, por sus propios clivajes y por los poderes fácticos, especialmente los económicos globalizados, los partidos políticos han resentido estas tensiones, debilidades o incertitudes, perdiendo su márgenes importantes de su capacidad mediadora entre el Estado y la sociedad civil, lo que conocemos como la crisis de representación Luego, más allá de las diferencias propias de la diversidad latinoamericana, por una parte - como dice Garretón- «los partidos deben enfrentar el problema de su capacidad para gobernar y, sobre todo, la posibilidad de hacer frente a la crisis de la política y la pérdida del rol referencial del Estado» ${ }^{143}$. Y, en segundo término, por sobre el camino que tracen los partidos, los movimientos sociales siguen adelante con sus proyectos, bajo sus propias dinámicas y subjetividades.

Paralelamente, el mercado, silente, constante y voraz, suma y sigue en sus procesos de acumulación del capital, de apropiación por desposesión de los bienes públicos y los bienes comunes ${ }^{144}$, de colonización, de hegemonía, donde los servicios que debía proveer el Estado han sido desplazados al sector priva$\mathrm{do}^{145}$. Podríamos decir, el Estado se ha mercantilizado y la sociedad civil tanto se moviliza como consume.

En definitiva, producido el «descuajeringamiento» de la matriz sociopolíti-

I43. GARRETÓN (2004) p. 80.

I44. SEOANE et al. (2OI2).

I45. Garretón (2OIO) p. 220. 
ca en América Latina, el escenario quedó abierto para las mediaciones de los propios movimientos sociales, que si bien es difícil se puedan desentender de los partidos políticos, especialmente en la medida que éstos sigan vinculados a las elites de poder, sin duda tampoco están supeditados a la exclusiva mediación partidaria golpeada por todos los factores, propios y externos, que hemos descrito. Pero, al mismo tiempo, movimientos y partidos hoy deben lidiar con las nuevas mediaciones del mercado, sus intersticios y expansión que cruzan la sociedad y avanza hegemónicamente. Al mismo tiempo, el reposicionamiento de la ciudadanía y formas de democracia arraigadas socialmente ( «desde abajo»), emergen como nuevos paradigmas con potencia aglutinante, mostrando un camino concreto de profundización democrática y justicia social que los partidos políticos pueden tomar y por el que ya marchan los movimientos sociales.

\section{Referencias}

Albó, X. (2004): «Indentidad y acceso indígena al poder». En Memoria del Foro Internacional sobre Participación de los Pueblos Indígenas originarios y formas de representación (La Paz, Fondo Indígena), pp. I40-I 50.

Altvater, Elmar (2006): «¿Existe un marxismo ecológico?». En, Borón, Atilio, Amadeo, Javier y González, Sabrina (Eds.) (2006): La teoría marxista hoy, problemas y perspectivas (Buenos Aires, CLACSO), pp. 34 I-363.

Altvater, Elmar y Mahnkopf, Birgit (2006): Las limitaciones de la globalización. Economía, ecología y política de la globalización (Madrid, Siglo $\mathrm{XXI)}$.

Amin, Samir (I995): «Introducción. Mundialización y acumulación capitalista». En Amin, Samin y González Casanova, Pablo. La nueva organización capitalista mundial vista desde el sur. Vol. I. Mundialización y acumulación (México, Anthropos) pp. I I-50.

Barragán, Rossana (2006): «Más allá de lo mestizo, más allá de lo Aymara: organización y representaciones de clase y etnicidad en La Paz». En América Latina Hoy, $\mathrm{N}^{\circ} 43$, pp. I07-I30.

BAROzET, Emmanuelle (2003): «Movilización de recursos y redes sociales en los neopopulismos: Hipótesis de trabajo para el caso chileno». En Revista de Ciencia Política, Vol. XXIII, No I, pp. 39-54.

BECK, Ulrich (I998): ¿Qué es la globalización? Falacias del globalismo, respuestas a la globalización (Barcelona, Paidos). 
Borón, Atilio (2000): Tras el Búho de Minerva. Mercado contra democracia en el capitalismo de fin de siglo (Buenos Aires, Fondo de Cultura Económica).

Calfío, Margarita y Velasco, Fernanda (2005): «Mujeres indígenas en América Latina: brechas de género o de etnia?». En Seminario Internacional Pueblos Indígenas y afrodescendientes de América Latina y el Caribe: relevancia y pertinencia de la información sociodemográfica para políticas y programas (Santiago, CEPAL).

CÁrdenas, Camila (20I4): «Representación de la Acción Política de los Estudiantes Chilenos: Movilización de Significados en Redes Sociales». En Última Década, Vol. 22, $\mathrm{N}^{\circ} 40$.

Castells, Manuel (2005): Globalización, desarrollo y democracia: Chile en el contexto mundial (Santiago, Fondo de Cultura Económica).

Castells, Manuel (20I2): Redes de indignación y esperanza: los movimientos sociales en la era de Internet (Madrid, Alianza Editorial).

Ceimm, Centro de estudios e información de la mujer multiétnica (2002): «El empoderamiento para garantizar la plena, activa y propositiva participación de las mujeres indígenas y el fortalecimiento del liderazgo (Documento referencial)». En Primera cumbre de mujeres indígenas de las América, Universidad de las regiones de la costa caribe nicaraguense (Oxaca, Ed. Oxaca).

Claros, Luis. y Viaña, Jorge (2009): «La interculturalidad como lucha contrahegemónica. Fundamentos no relativistas para una crítica de la de la». En Viaña, Jorge; Claros, Luis; Estermann, Josef; Fornet-Betancourt, Raúl; Garcés, Fernando; Quintanilla, Víctor Hugo y Ticona, Esteban. Interculturalidad crítica y descolonización Fundamentos para el debate (La Paz, Convenio Andrés Bello) pp. 8I-I47.

Domingo, Agustin (20I I): Ciudadanía multicultural, conflicto y cultura de la paz. (Temuco, Ediciones U.C. Temuco).

Escarárzaga, Fabiola (2006) «La comunidad indígena en las estrategias insurgentes en México, Perú y Bolivia». En Gutiérrez, Raquel y EscarárZAGA, Fabiola (Eds.). Movimiento indígena en América Latina: resistencia $y$ proyecto alternativo ( México, UAM, Volumen I) pp. I89-2 I 8.

Escobar, Arturo (2003): «Mundos y conocimientos de otro modo. El programa de investigación de modernidad/colonialidad latinoamericano». En Tabula Rasa, $\mathrm{N}^{\circ}$ I, Enero-diciembre de 2003, pp. 5 I-86.

FAUNDES, Juan Jorge (2013): «Integración regional, reformas a la justicia y 
respeto del estándar internacional de derechos humanos en los procesos penales seguidos contra indígenas movilizados socialmente». En Álvarez, Mario y Cippitani, Roberto (Coords.). Derechos Individuales e Integración Regional (Antología) (Roma, Perugia, México, ISEG), pp. 4I7-476. Disponible en: <http://www.academia.edu/9r96349/Derechos_Individuales_e_ Integracio_n_regional_antologi_a_> [Fecha de consulta: I de julio de 20I6]. FAUNDES, Juan Jorge (2015a): «Recomprensión intercultural de los derechos humanos. Apuntes para el reconocimiento de los pueblos indígenas en América Latina». En Justiça do Direito, Universidade de Passo Fundo, Vol. 29, $\mathrm{N}^{\circ}$ I 2015 , pp. IO8-I 30.

Faundes, Juan Jorge (20 I 5 b): «El consenso democrático de Habermas. Debates frente a la demanda por el reconocimiento de la identidad cultural de los pueblos indígenas en América Latina». En Gt Ética e Cidadania da Asociaciação Nacional de Pos-Graduação em Filosofía [ANPOF] (Brasil, ANPOF), Aceptada, primer semestre 2016.

FAUNDES, Juan Jorge (201 $5 \mathrm{c}$ ): «Pensando un horizonte democrático, pluralista e intercultural para el reconocimiento de los pueblos indígenas en América Latina, desde una relectura crítica a Laclau y Mouffe». En Revista Chilena de Derecho y Ciencia Política, Vol. 6, $\mathrm{N}^{\circ}$ 3, septiembre-diciembre 20I 5 , U.C. Temuco.

Faundes, Juan Jorge (2016): Modelos de reconocimiento de los Pueblos Indígenas en América Latina. Bolivia y Chile. Análisis de un contraste (Mérida Venezuela, Fondo Editorial del Centro de Estudios Políticos y Sociales de América Latina (CEPSAL) de la Facultad de Ciencias Jurídicas y Políticas de la Universidad de Los Andes). En prensa.

Fornet-Betancourt, Raúl (2007): «La filosofía intercultural desde la perspectiva latinoamericana». En Solar, $\mathrm{N}^{\circ}$ 3, Vol. 3, pp. 23-40.

Fornet-BetANCOURT, Raul (2OII): La Filosofía Intercultural y la dinámica del reconocimiento (Temuco, Ediciones U.C. Temuco).

Garcés, Mario (2003): Los movimientos sociales en América Latina en el actual contexto (Córdoba, Escuela de Trabajo Social Universidad Nacional de Córdova). Disponible en: <http://www.ongeco.cl/wp-content/ uploads/20I 5/o4/Los_movimientos_sociales_en_Am \% C $3 \%$ A 9rica_ Latina_C\% 3 \% $\% 3$ rdoba2003.pdf> [Fecha de consulta: I de julio de 20I6].

García Linera, Álvaro (2004): «Crisis de estado y sublevaciones indígeno plebeyas». En García Linera, Álvaro; Tapia, Luis y Prada, Raul. Memorias de Octubre (La Paz, Comuna, Muela del Diablo) pp. 423-446. 
GARCía Linera, Álvaro (2006): «El evismo: lo nacional popular en acción». En OSAL, Observatorio Social de América Latina, VII, $\mathrm{N}^{\circ}$ I9, enero-abril 2006, pp. 25-32.

García Linera, Álvaro (2OI I): «El movimiento social empuja el cambio político». En Punto Final, Septiembre 20I I, pp. I6-г 8.

Garretón, Manuel Antonio (2000): La sociedad en que viviremos (Santiago, LOM).

GARretón, Manuel Antonio (200I): Cambios sociales, actores y acción colectiva en América Latina (Santiago, CEPAL, Naciones Unidas).

Garretón, Manuel Antonio (2002): «La transformación de la acción colectiva en América Latina». En Revista de la Cepal, N 76, pp. 7-24.

Garretón, Manuel Antonio (2004a): «Discusión de tres tesis para un marco teórico para el proyecto sobre el Desarrollo de la democracia en América Latina: estado, percepciones ciudadanas, indicadores y agentes». En La Democracia en América Latina. El Debate Conceptual de la Democracia (Buenos Aires, PNUD), pp. 225-239.

Garretón, Manuel Antonio (2004b): «La indispensable y problemática relación entre partidos y democracia en América Latina». En PNUD (Ed.), La democracia en América Latina. Hacia una democracia de ciudadanas y ciudadanos. Contribuciones para el debat (Buenos Aires, Aguilar - Altea Alfaguara), pp. 72-97.

GARretón, Manuel Antonio (2010): «La problemática actual de América Latina y las respuestas en juego". En Osorio, Alejandro y Salazar, Mauro (Eds.). Democracia y antagonismo en el Chile contemporaneo. perspectivas post-transcicionales (Santiago, Akhilleus).

GARRETón, Manuel Antonio (2012): Neoliberalismo corregido y progresismo limitado. Los gobiernos de la Concertación en Chile, I990-2010 (Santiago, CLACSO, Editorial ARCIS).

Golcovic, Igor (1996): «Movimientos Sociales en la Encrucijada. Entre la integración y la Ruptura». En Última Década, $\mathrm{N}^{\circ} 5$, pp. I-I4.

GoICovic, Igor (I998): Sujetos, mentalidades y movimientos sociales en Chile (Santiago, CIDPA).

Gómez, Juan Carlos (2010): Política, democracia y ciudadanía en una sociedad neoliberal (Chile: I990-2010) (Santiago, Arcis - CLACSO).

Gómez, Juan Carlos (20II): «Movimientos sociales, proyectos populares y democracia. Escenarios sopciopolíticos latinoamericanos I998-20I I». En América Latina, $\mathrm{N}^{\circ}$ I I, Universidad Arcis, pp. 49-67. 
Gómez, Juan Carlos. (20I2): «Los escenarios del cambio y del estancamiento político en América Latina». En Estay Reyno, Jaime; Lara, Claudio y Silva, Consuelo (Eds.). El neoliberalismo y su crisis. Causas, esenarios y posibles desenvolvimientos (Santiago, REDEM), pp. I63-I77.

Gómez, Magdalena (2002): «Derecho Indígena y Constitucionalidad». En Krotz, Esteban. Antropología Jurídica: Perspectivas Socioculturales en el Estudio de Derecho (Iztapalapa, Editorial Anthropos) pp. 235-278.

HABERMAs, Jünger (I999): La inclusión del otro. Estudios sobre teoría política (Barcelona, Paidós).

Honneth, Axel (I997): La lucha por el reconocimiento. Por una gramática moral de los conflictos (Barcelona: Crítica).

Kats, Claudio (20I2): «Los atolladeros de la economía latinoamericana». En Estay, Jaime, Lara, Claudio y Silva, Consuelo (Eds.). El neoliberalismo $y$ su crisis. Causas, esenarios y posibles desenvolvimientos (Santiago, REDEM), pp. I I 2-I 26.

KETTERER, Lucy (20I I): «Mujeres indígenas latinoamericanas y política: prácticas «diferentes para»». En Punto Género, Universidad de Chile, $\mathrm{N}^{\circ} \mathrm{I}$.

Kymlicka, Will (I995): Multicultural Citizenship (Oxford, Oxford University Press).

KymlickA, Will (2009): Las odiseas multiculturales. Las nuevas politicas internacionales de la diversidad (Barcelona, Paidos).

LAClau, Hernesto (2005): La razón populista (Buenos Aires, Fondo de Cultura Económica).

Laclau, Hernesto y Moufe, Chantal (2004): Hegemonía y estrategia socialista. Hacia una radicalización de la democracia (Londres - Buenos Aires, Fondo de Cultura Económica).

LECHNER, Norbert (2002): Las sombras del mañana. la dimensión subjetiva de la política (Santiago, LOM).

Martins, Paulo (2009): «Redes sociales: un nuevo paradigma en el horizonte sociológico». En Cinta Moebio, $\mathrm{N}^{\circ}$ 35, septiembre 2009, pp. 88-109. Disponible en: <http://dx.doi.org/I0.4067/So7 I7-554X2009000200002> [Fecha de consulta: I de julio de 20I6].

Mirza, Christian (2006): Movimientos sociales y sistemas politicos en América Latina: La construcción de nuevas democracias (Buenos Aires, CLACSO).

Orellana, Lorgio (2006): "Hacia una caracterización del gobierno de Evo Morales». En OSAL, Observatorio Social de América Latina, Vol. VII, N I9, enero-abril 2006, pp. 45-54. 
Prada, Raúl (20I2): «Espesores de una coyuntura candente». Disponible en: $<$ http://www.bolpress.com/art.php?Cod=20I2030706> [Fecha de consulta: I de julio de 2016].

Quijano, Anibal (2002): "Colonialidad del poder, globalización y democracia». En Trayectorias. Revista de ciencias sociales de la Universidad Autónoma de Nueva León, $N^{\circ}$ 4, 7/8, septiembre-abril 2002, pp. 58-i I6.

Reguillo, Rossana. (200I): Pensar la cultura con y después de Bordeau. Rev. Univ. Guadalajara. Disponible en: <http://www.cge.udg.mx/revistaudg/ rug24/bourdieu4.html>. [Fecha de consulta: I de julio de 2016].

Revilla, Marisa (I996): «El Concepto de movimiento Social Acción, Identidad y Sentido». En Última Década, $\mathrm{N}^{\circ}$ 5, pp. I-I 8.

Revilla, Marisa (2005): "Ciudadanía y acción colectiva en América Latina». En Estudios Políticos, $\mathrm{N}^{\circ} 27$, pp. 29-4I.

Revilla, Marisa (2010): "América Latina y el presente de la «rebelión del coro»». En Nueva Sociedad, No 227, mayo-junio 20Io, pp. 52-67.

Rivera, Silvia (2004): «La noción de «derecho o las paradojas de la modernidad postcolonial: indígenas y mujeres en Bolivia». En Aportes Andinos, $\mathrm{N}^{\circ}$ I I Aportes sobre diversidad, diferencia e identidad, Universidad Andina Simon Bolivar.

Rivera, Silvia y Borragón, Rossana (I997): Debates post coloniales. Una introducción a los estudios de la subalternidad (Bogotá, SEPHIS).

SAntos, Boaventura de Sousa (200I): "Los nuevos movimientos sociales». En OSAL, Observatorio Latinoamericano de Ciencias Sociales, septiembre 200I. Disponible en: <http://www.boaventuradesousasantos.pt/media/ pdfs/Los_nuevos_movimientos_sociales_OSAL200I.PDF> [Fecha de consulta: I de julio de 20I6].

Santos, Boaventura de Sousa (2004): Reinventar la Democracia. Reinventar el Estado (Quito, Abya-Yala).

SCHERER-WARrEN, Ilse (2005): «Redes sociales y de movimiento en la sociedad de la información», En Nueva sociedad, $\mathrm{N}^{\circ}$ I96, marzo-abril 2005, pp. 77-92.

Seoane, José; Algranati, Clara y Taddei, Emili (20I2): «Realidades y desafíos polítios de «Nuestra América». Una década de luchas sociales y cambios políticos en América Latina». En América Latina, No I I, pp. 25-47.

Somuano, Fernanda (2007): Movimientos sociales y patidos políticos en América Latina: una relación cambiante y compleja. En Política y cultura, $\mathrm{N}^{\circ}$ 27, pp. 3I-53. 
STEFAnOni, Pablo (2006): «El nacionalismo indígena en el poder». En OSAL Observatorio Social de América Latina, Vol. VII, N I9, enero- abril 2006 , pp. 37-44.

Svampa, Maristella (2007): «Movimientos sociales y escenario político: las nuevas inflexiones del paradigma neoliberal en América Latina». En OSAL Observatorio Social de América Latina, septiembre 2007. Disponible en: <http://documents.tips/documents/svampa-56 db4df4cbf6e.html> [Fecha de consulta: I de julio de 20I6].

TAPIA, Luis (2007): La igualdad es cogobierno (La Paz, Plural-CIDES-UMSAASDI-SAREC).

TAPIA, Luis (2009). "Movimientos sociales, movimientos societales y los no lugares de la política». En Cuadernos del pensamiento crítico latinoamericano, $\mathrm{N}^{\circ} \mathrm{I} 7$, año 2-3, pp. 2-4.

TAPIA, Luis (20I I): El estado de derecho como tiranía (La Paz, CIDES-UMS - Autodeterminación).

TAYlor, Charles (I992): Multiculturalism and «the Politics of Recognition» (Princeton, Princeton University Press).

Touraine, Alain (I989): América Latina, política y sociedad (Madrid, Espasa).

ZegadA, María Teresa (20I3): Entrevista: 20-2 I de mayo de 20I3. Entrevistador: Juan Jorge Faundes Peñafiel, Cochabamba.

Zegada, María Teresa; Arce, Claudia; Canedo, Gabriela y Quispe, Albert (20I I). Democracia de los márgenes: transformaciones en el campo politico boliviano (La Paz, CLACSO, Muela del Diablo).

Zibechi, Raúl (2003): «Los movimientos sociales latinoamericanos: tendencias y desafíos. En OSAL, Observatorio Social de América Latina, $\mathrm{N}^{\circ}$ 9, enero 2003, pp. I 85-I 88 .

Zibechi, Raúl (2006a): «Movimientos sociales: nuevos esenarios y desafíos inéditos». En OSAL, Observatorio Social Latinoamericano, $\mathrm{N}^{\circ}$ 2 I, año VII, diciembre 2006, pp. 22I-230.

Zibechi, Raúl (2006b): «Estrategias políticas de los movimientos indígenas». En Gutiérrez, Raquel y Escarárzaga, Fabiola (Eds.). Movimiento indigena en América Latina: resistencia y proyecto alternativo (México, UAM, Volumen I) pp. 474-483).

ZibeCHI, Raúl (2009): "Gobiernos y movimiento: entre la autonomía y las nuevas formas de dominación». En Hoetmer, Raphael. Repensar la política 
desde América Latina.Cultura, Estado y movimientos sociales (Lima, Universidad Mayor de San Marcos) pp. I85-I94.

ZÚÑIGA, Yanira (2009): «La "generalización» de la ciudadanía. Apuntes sobre el rol de la diferencia sexual en el pensamiento feminista». En Revista de Derecho, Vol. XXII, $\mathrm{N}^{\circ}$ 2, diciembre 2009, pp. 39-64. 